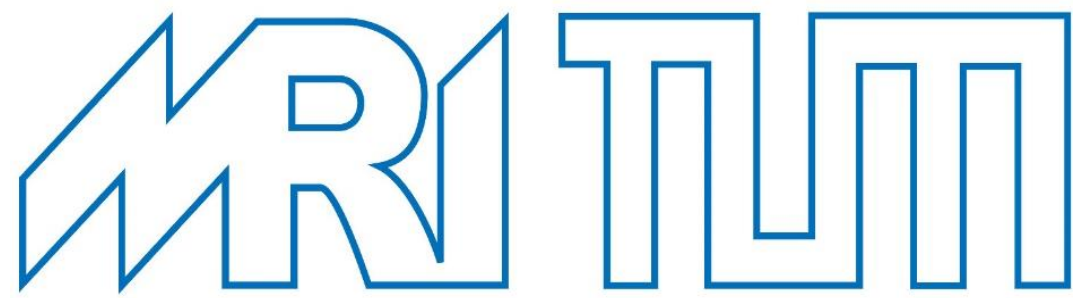

II. Medizinische Klinik und Poliklinik

Klinikum rechts der Isar

Technische Universität München

\title{
Comparison of Endoscopic Sphincterotomy Techniques after Billroth II Gastrectomy Using a Novel Mechanical Simulator
}

\author{
Mohamed Abdelhafez Zaki Abdelrahim
}

Vollständiger Abdruck der von der Fakultät für Medizin der Technischen Universität München zur Erlangung des akademischen Grades eines Doktors der Medizin genehmigten Dissertation.

Vorsitzender: Prof. Dr. Jürgen Schlegel

Prüfer der Dissertation: $\quad$ 1. Prof. Dr. Roland M. Schmid

2. apl. Prof. Dr. Monther Bajbouj

Die Dissertation wurde am 13.06.2017 bei der Technischen Universität München eingereicht und durch die Fakultät für Medizin am 28.03.2018 angenommen. 
Due to the relevance of the study results, parts of this thesis have been published beforehand or waiting for publishing:

Fimberger E, Abdelhafez M, Schmid RM, Delius S. A novel mechanical simulator for cannulation and sphincterotomy after Billroth II or Roux-en-Y reconstruction. Endosc Int Open. 2016 Aug; 4(8).

Abdelhafez M, Frimberger E, Klare P, Haller B, Schmid RM, Delius S. Comparison of Endoscopic Sphincterotomy Techniques after Billroth II Gastrectomy Using a Novel Mechanical Simulator. Surgical Endoscopy. Accepted waiting for publishing. May 2017. 


\section{Abbreviations}

EST Endoscopic sphincterotomy

BII Billroth II

ERCP Endoscopic retrograde cholangiopancreatography

MDP Major duodenal papilla

CBD Common bile duct

PD Pancreatic duct

MRCP Magnetic resonance cholangiopancreatography

MRI Magnetic resonance imaging

CT Computed tomography

EUS Endoscopic ultrasonography

ASGE American Society of Gastrointestinal Endoscopy

SOD Sphincter of Oddi dysfunction

ICU Intensive care unit

GOO Gastric outlet obstruction

VR Virtual reality

FVE Forward-viewing endoscope

SVE Side-viewing endoscope

SD Standard deviation 


\section{Abstract:}

Background and Aims: A postsurgical anatomy after Billroth II reconstruction renders endoscopic sphincterotomy (EST) more challenging. Although different EST techniques for such a situation exist, comparative studies are lacking. The aim of the study was to compare the efficacy of different EST techniques using a novel mechanical simulator.

\section{Methods:}

Ten expert endoscopists performed 6 different EST techniques on a novel mechanical Billroth II (BII) simulator in a random sequence. The EST techniques were: 1) standard sphincterotome used with a side-viewing endoscope, 2) BII sphincterotome used with a side-viewing endoscope, 3) needle-knife EST guided by biliary endoprosthesis used with a side-viewing endoscope, 4) standard sphincterotome used with a forward-viewing endoscope, 5) Bll sphincterotome used with a forward-viewing endoscope, 6) needle-knife EST guided by biliary endoprosthesis used with a forward-viewing endoscope. The results of videotaped ESTs were evaluated by a blinded expert and duration for each EST modality was calculated.

Results: Needle-knife EST guided by endoprosthesis was rated superior to EST using a Bll sphincterotome $(p=0.017)$ or a standard sphincterotome $(p<0.001)$. EST by using the BII sphincterotome was significantly faster than EST with the needle-knife $(p=0.004)$ and the standard sphincterotome $(p=0.005)$. There were no differences between the use of a forward-viewing endoscope and a side-viewing endoscope.

Conclusion: In an ex-vivo model for EST in B II gastrectomy needle-knife EST guided by endoprosthesis achieved superior ratings in comparison to the use of a BII sphincterotome and standard sphincterotome, although it was more time-consuming. 


\section{Abstract (German):}

\section{Einleitung:}

Nach Gastrektomie und Rekonstruktion nach Billroth II (BII) ist die endoskopische Papillotomie (EPT) erschwert. Obwohl verschiedene Techniken für eine solche Situation existieren, fehlt bislang eine vergleichende Studie. Ziel der aktuellen Studie war es, die Effektivität der verschiedenen Techniken in einem neuen mechanischen Simulator zur Bll-Papillotomie gegenüberzustellen.

\section{Methoden:}

10 erfahrene Endoskopiker führten 6 verschiedene EPT-Techniken in einer randomisierten Reihenfolge im mechanischen Bll-Simulator durch. Die EPT-Techniken waren: 1) StandardPapillotom mit Duodenoskop, 2) Bll-Papillotom mit Duodenoskop, 3) Nadelmesser-EPT über Stent mit Duodenoskop, 4) Standard-Papillotom mit pädiatrischem Koloskop, 5) Bll-Papillotom mit pädiatrischem Koloskop und 6) Nadelmesser-EPT über Stent mit pädiatrischem Koloskop. Die Video-Aufzeichnungen der EPTs wurden durch einen weiteren verblindeten ERCP-Experten ausgewertet. Jede Methode wurde auf einer Skala von 1-10 bewertet. Die Zeiten für die Durchführung der jeweiligen EPT wurden erfasst.

\section{Ergebnisse:}

Die Nadelmesser-EPT über Stent war hinsichtlich der Effektivität der EPT mit BII-Papillotom $(p=0,017)$ und der EPT mit Standard-Papillotom ( $p<0,001$; Tabelle) überlegen. Eine EPT mittels BII-Papillotom konnte signifikant schneller durchgeführt werden als die Nadelmesser-EPT über Stent $(p=0,004)$ und die EPT mit Standard-Papillotom $(p=0,005)$. Hinsichtlich des Einsatzes eines Duodenoskops (Seitblick-Optik) oder pädiatrischen Koloskops (prograde Optik) ergaben sich keine Unterschiede.

\section{Zusammenfassung:}

Bei einem ex-vivo Model für die Papillotomie bei BlI-Anatomie ließen sich mit der NadelmesserEPT über Stent bessere Ergebnisse als mit den anderen Methoden erzielen, auch wenn sie mit einem erhöhten Zeitaufwand verbunden war. Ein Standard-Papillotom sollte in einer solchen Situation nicht verwandt werden. 


\section{Table of Contents}

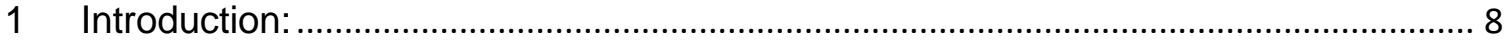

$1.1 \quad$ Endoscopic retrograde cholangiopancreatography (ERCP):............................ 8

1.1.1 Historical background and introduction ....................................................... 8

1.1.2 Indications for ERCP ........................................................................ 9

1.1.3 Preprocedure preparation....................................................................... 11

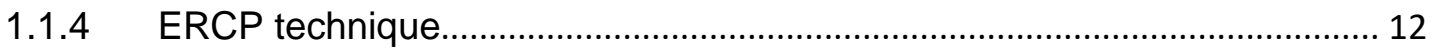

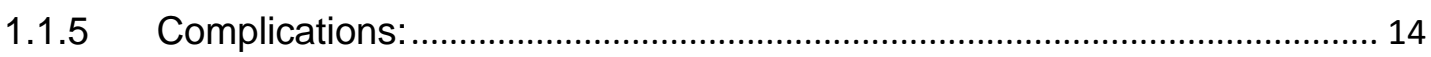

1.2 Billroth II reconstruction .............................................................................. 19

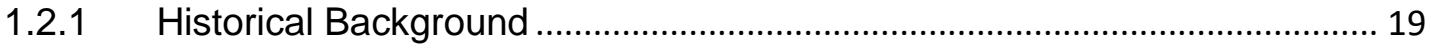

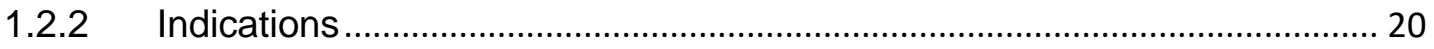

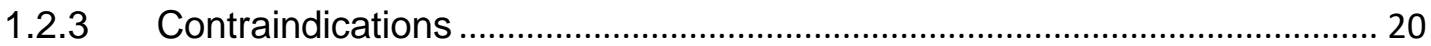

1.2.4 Techniques …………………………………………………………. 21

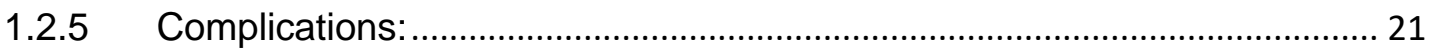

1.3 ERCP challenges after Billroth II reconstruction ................................................. 23

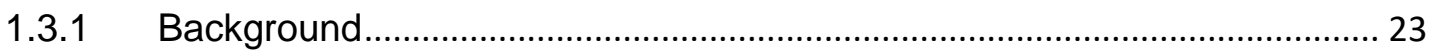

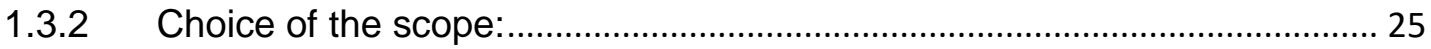

1.3.3 Intubation of the afferent loop ..................................................................... 27

1.3.4 Cannulation of the papilla ............................................................................ 28

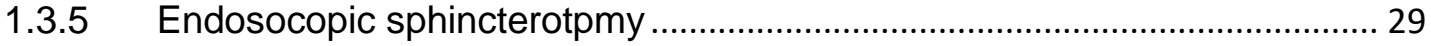

1.4 Endoscopic Simulators .................................................................................. 31

1.4.1 Types of simulators ……………………………......................................... 31

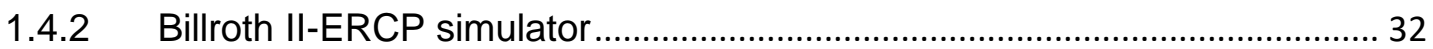

1.5 Problem statement and objectives ................................................................. 33

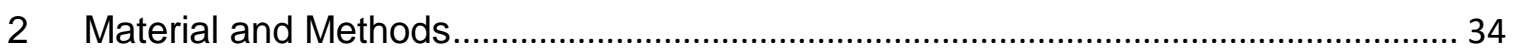

2.1 Study design ................................................................................................ 34

2.2 The mechanical simulator .............................................................................. 34

2.3 Expert participant ............................................................................................ 37

2.4 Endoscopic Sphincterotomy techniques and equipments.................................. 38

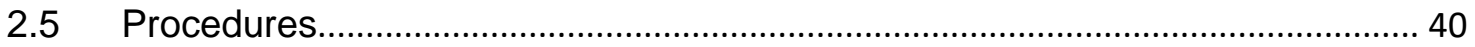

2.6 Blinded evaluation of ESTs and the efficacy score .......................................... 41

2.7 Outcome Variables and Data analysis .............................................................. 41 


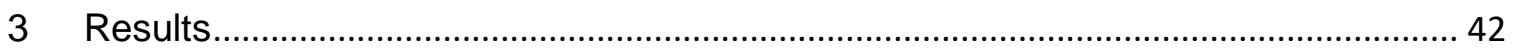

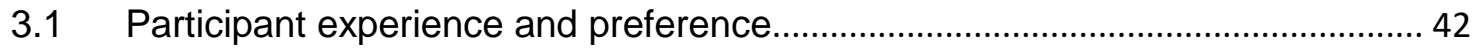

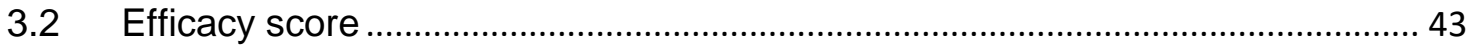

3.2.1 Overview of efficacy scores ............................................................................. 43

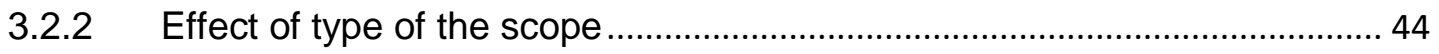

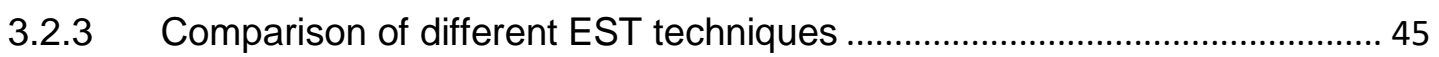

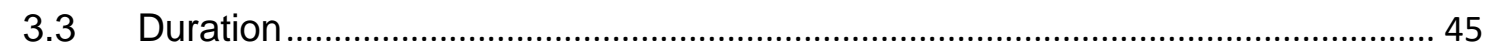

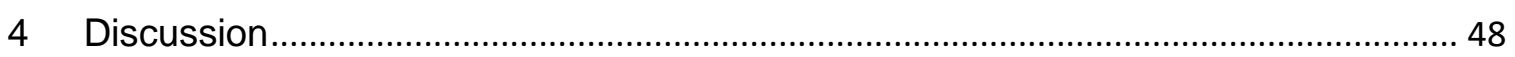

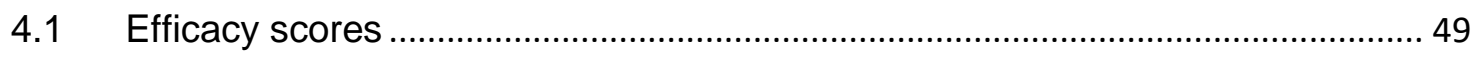

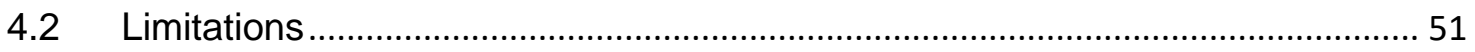

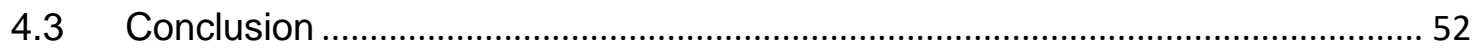

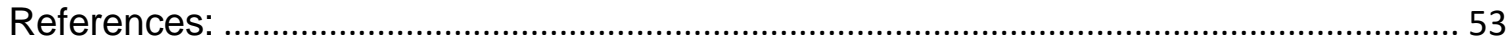

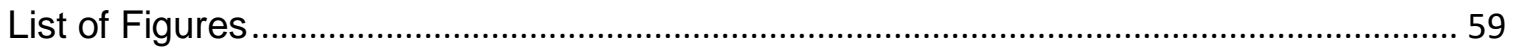

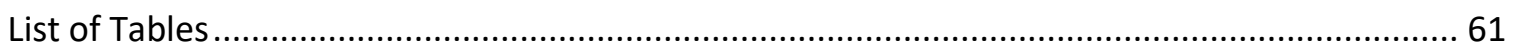

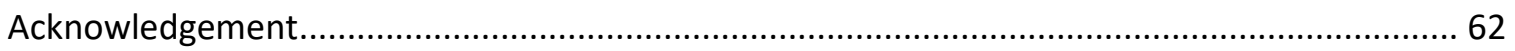




\section{Introduction:}

\subsection{Endoscopic retrograde cholangiopancreatography (ERCP):}

\subsubsection{Historical background and introduction}

Endoscopic cannulation of the common bile duct through the major duodenal papilla was first described in 1968 (McCune, Shorb, \& Moscovitz, 1968). Long side viewing endoscopes were developed by several Japanese groups working with instrument manufacturers (Kasugai, Kuno, Aoki, Kizu, \& Kobayashi, 1971; Takagi, Ikeda, Nakagawa, Sakaguchi, Takahashi, Kumakura, Maruyama, Someya, Nakano, Takada, Takekoshi, \& Kin, 1970). The technique then spread throughout Europe in the early seventies and was considered as a valuable diagnostic technique (Cotton, 1972; Cotton, Blumgart, Davies, Pierce, Salmon, Burwood, Lawrie, \& Read, 1972; Wiesner, Weiss, \& Anacker, 1972). A great leap for ERCP was achieved by the development of the therapeutic techniques, namely the endoscopic sphincterotomy in the mid-seventies (Classen \& Demling, 1974; Kawai, Akasaka, Murakami, Tada, \& Koli, 1974) and biliary stenting about 5 years later (Soehendra \& Reynders-Frederix, 1980).

Endoscopic retrograde cholangiopancreatography (ERCP) is an advanced endoscopic procedure in which a side-viewing endoscope and different instruments are used to access the major duodenal papilla (MDP). After localizing the MDP in the duodenum with the side-viewing endoscope, different instruments and techniques are used to cannulate the common bile duct (CBD) and/or pancreatic duct (PD). A contrast agent is injected to opacify the biliary system and/or the pancreatic duct, allowing radiologic visualization, diagnosis and different therapeutic interventions (Canard, Lennon, Létard, Etienne, \& Okolo, 2011). Endoscopic retrograde cholangiopancreatography (ERCP) technique is regarded as a complex and advanced endoscopic procedure because of its need for a variety of instruments and accessories as well as its long learning curve which is needed to develop competency with this technique. In addition, ERCP technique is challenged by higher risk of complications in comparison to any other endoscopic procedure (Committee, Chathadi, Chandrasekhara, Acosta, Decker, Early, Eloubeidi, Evans, Faulx, Fanelli, Fisher, Foley, Fonkalsrud, Hwang, Jue, Khashab, Lightdale, Muthusamy, Pasha, Saltzman, Sharaf, Shaukat, Shergill, Wang, Cash, \& DeWitt, 2015). 
Like all other endoscopic procedures safety and quality of ERCP can be guaranteed through a variety of objective elements which include (Young HS, 1998):

- Appropriate indication

- Sedation and monitoring

- Patient age and clinical condition

- Type of procedure (diagnostic or therapeutic)

- Setup and instruments

- Training and competence

\subsubsection{Indications for ERCP}

ERCP is essentially a procedure performed by cannulation of the pancreatic duct and/or biliary tree for diagnosis and/or therapy. The diagnostic indications for ERCP have been diminished with the development of less invasive diagnostic techniques like Magnetic resonance cholangiopancreatography (MRCP) and endoscopic ultrasonography (EUS) (Giljaca, Gurusamy, Takwoingi, Higgie, Poropat, Stimac, \& Davidson, 2015; Hekimoglu, Ustundag, Dusak, Erdem, Karademir, Aydemir, \& Gundogdu, 2008). The therapeutic indications have broadened with the increasing performance of laparoscopic cholecystectomy (Cohen, Bacon, Berlin, Fleischer, Hecht, Loehrer, McNair, Mulholland, Norton, Rabeneck, Ransohoff, Sonnenberg, \& Vannier, 2002). Indications of ERCP according to the American Society of Gastrointestinal Endoscopy (ASGE) in 2012 and 2015 are (Committee, Chathadi, Chandrasekhara, Acosta, Decker, Early, Eloubeidi, Evans, Faulx, Fanelli, Fisher, Foley, Fonkalsrud, Hwang, Jue, Khashab, Lightdale, Muthusamy, Pasha, Saltzman, Sharaf, Shaukat, Shergill, Wang, Cash, \& DeWitt, 2015): “

- Jaundice with suspicion of biliary obstruction

- Clinical and biochemical or imaging suspicion of biliary and/or pancreatic duct tract obstruction, even without jaundice.

- Symptoms and signs highly suggestive of pancreatic malignancy when direct imaging (e.g. endoscopic ultrasonography (EUS), ultrasound, computed tomography (CT), magnetic resonance imaging (MRI) are equivocal or normal.

- Acute biliary pancreatitis with concomitant cholangitis or biliary obstruction.

- Pancreatitis of unknown etiology.

- Preoperative evaluation of the patient with chronic pancreatitis and/or pseudocyst. 
- Evaluation of the sphincter of Oddi by manometry in patients with suspected type Il sphincter of Oddi dysfunction (SOD). Manometry is not indicated for patients with type I SOD (empiric sphincterotomy is treatment of choice in these patients), and it is not recommended in suspected type III SOD because of its low diagnostic yield and high risk of post-ERCP pancreatitis.

- Endoscopic sphincterotomy:

- Choledocholithiasis,

- Papillary stricture or SOD,

- To enable insertion of biliary stents or dilation of biliary strictures,

- Choledochocele involving the major papilla,

- Ampullary carcinoma in patients who are not fit for surgery,

- To facilitate pancreatic duct cannulation.

- Stent placement to bridge benign or malignant strictures, fistula, postoperative bile leak, or in high-risk patients with large common duct stones.

- Dilation of ductal strictures.

- Balloon dilation of the papilla.

- Nasobiliary tube placement.

- Pancreatic pseudocyst drainage in appropriate cases.

- Biopsies from pancreatic or bile ducts.

- Ampullectomy of adenomatous neoplasms of the major papilla.

- Therapy of disorders of the biliary and pancreatic ducts.

- Facilitation of cholangioscopy and/or pancreatoscopy.

ERCP is generally not indicated in:

- Assessment of abdominal pain of unknown etiology with symptoms suggestive of pancreatic or biliary origin. In such patients magnetic resonance cholangiography (MRCP) and EUS can be a more effective and safer alternatives.

- Prior to laparoscopic cholecystectomy when signs of biliary system obstruction are absent.

- Evaluation of the gallbladder if there is no evidence of bile duct pathology.

- Assessment of an already diagnosed pancreatic malignancy unless endoscopic intervention is palnned." 


\subsubsection{Preprocedure preparation}

Generally there is no recommendations to run a routine preprocedure laboratory testing, electrocardiography, or chest X-ray (Pasha, Acosta, Chandrasekhara, Chathadi, Eloubeidi, Fanelli, Faulx, Fonkalsrud, Khashab, Lightdale, Muthusamy, Saltzman, Shaukat, Wang, \& Cash, 2014). However, these preprocedure tests should be kept for selected cases based on general medical condition and the risk factors of the patient. Complications can occur in up to $5 \%$ of patients who undergo ERCP (e.g. post-ERCP pancreatitis, bleeding, infection, and perforation). Therefore, some laboratory tests (e.g. coagulation profile) should be done prior to the procedure, if they were not done during the primary evaluation of the patient.

The American Society of Gastrointestinal Endoscopy (ASGE) has recommended the following preprocedure testing in the 2014 guidelines (Pasha, Acosta, Chandrasekhara, Chathadi, Eloubeidi, Fanelli, Faulx, Fonkalsrud, Khashab, Lightdale, Muthusamy, Saltzman, Shaukat, Wang, \& Cash, 2014): “

- Pregnancy testing for women of childbearing when exclusion of pregnancy is uncertain or when there is a history suggestive of a current pregnancy (particularly if fluoroscopy will be used).

- Coagulation profile for patients with active bleeding, a known or suspected bleeding disorder (including a history of abnormal bleeding), an increased risk of bleeding due to medication use (e.g. ongoing anticoagulant use, prolonged antibiotic use), prolonged biliary obstruction, malnutrition, or other conditions associated with acquired coagulopathies.

- Chest imaging for patients with newly developed respiratory symptoms or heart failure.

- Blood picture for patients with preexisting significant anemia or active bleeding, or if there is a high risk of significant blood loss during the procedure.

- Blood typing for patients with active bleeding or anemia who are likely to need a blood transfusion.

- Serum chemistry testing for patients with significant endocrine, renal, or hepatic dysfunction if medications are to be used that may further impair function." 


\subsubsection{ERCP technique}

A side viewing endoscope is used to localize the major duodenal papilla, which is located on the medial wall of the descending duodenum. The papilla can be cannulated by using an ERCP plastic catheter or ERCP sphincterotome which is passed through the working channel of the endoscope and directed at the orifice of the papilla. Different types of ERCP guidewires can be used to facilitate the cannulation (Klaus F.R. Schiller, 2002).

After achievement of deep selective cannulation of the biliary and/or pancreatic ducts a contrast material is injected under fluoroscopic control to opacify the biliary ducts and/or pancreatic duct in order to establish a proper diagnosis. Multiple radiographs are taken, for documentation, as appropriate (Klaus F.R. Schiller, 2002; Petter Cotton, 2005). (Figure $1,2)$.

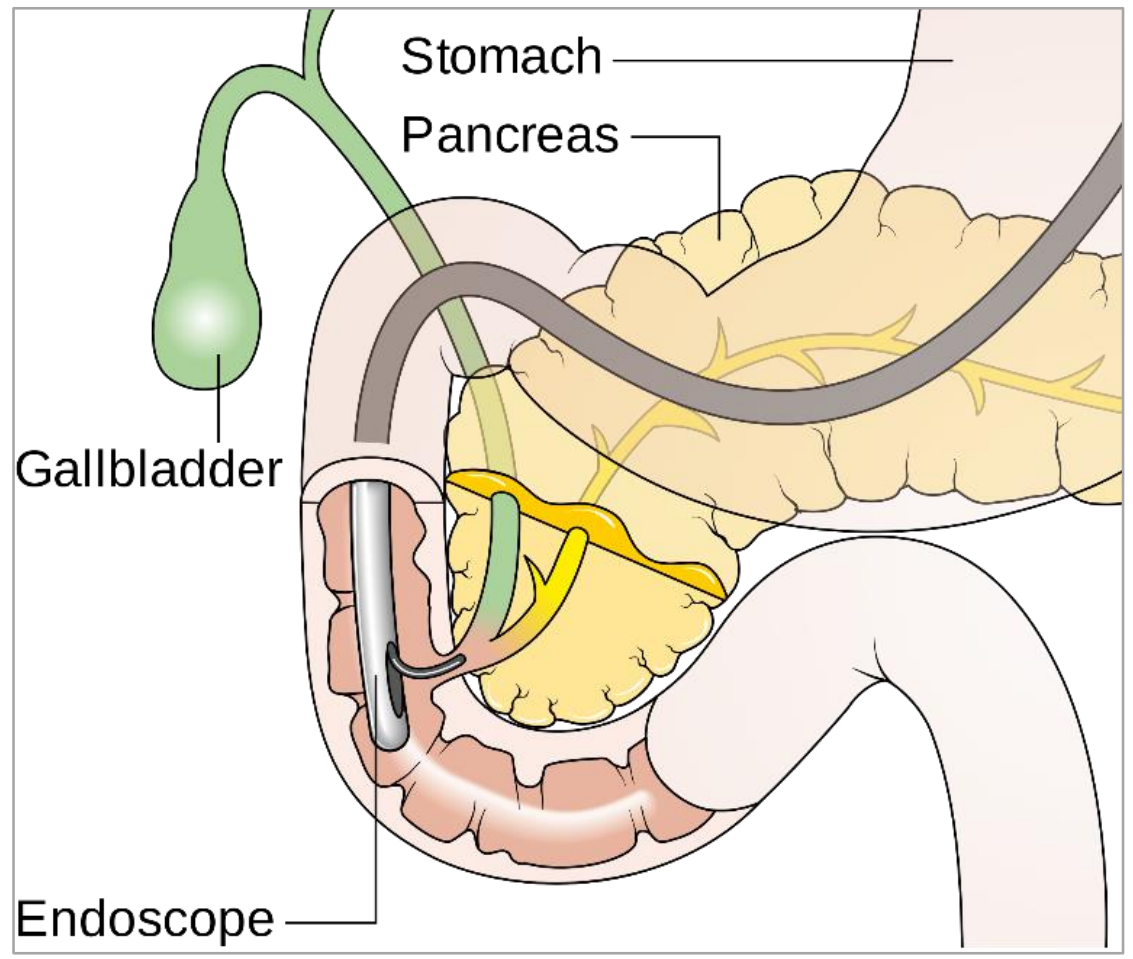

Figure 1. Cannulation of the bile duct through the papilla by using a side viewing duodenoscope (Cancer Research UK / Wikimedia Commons) 


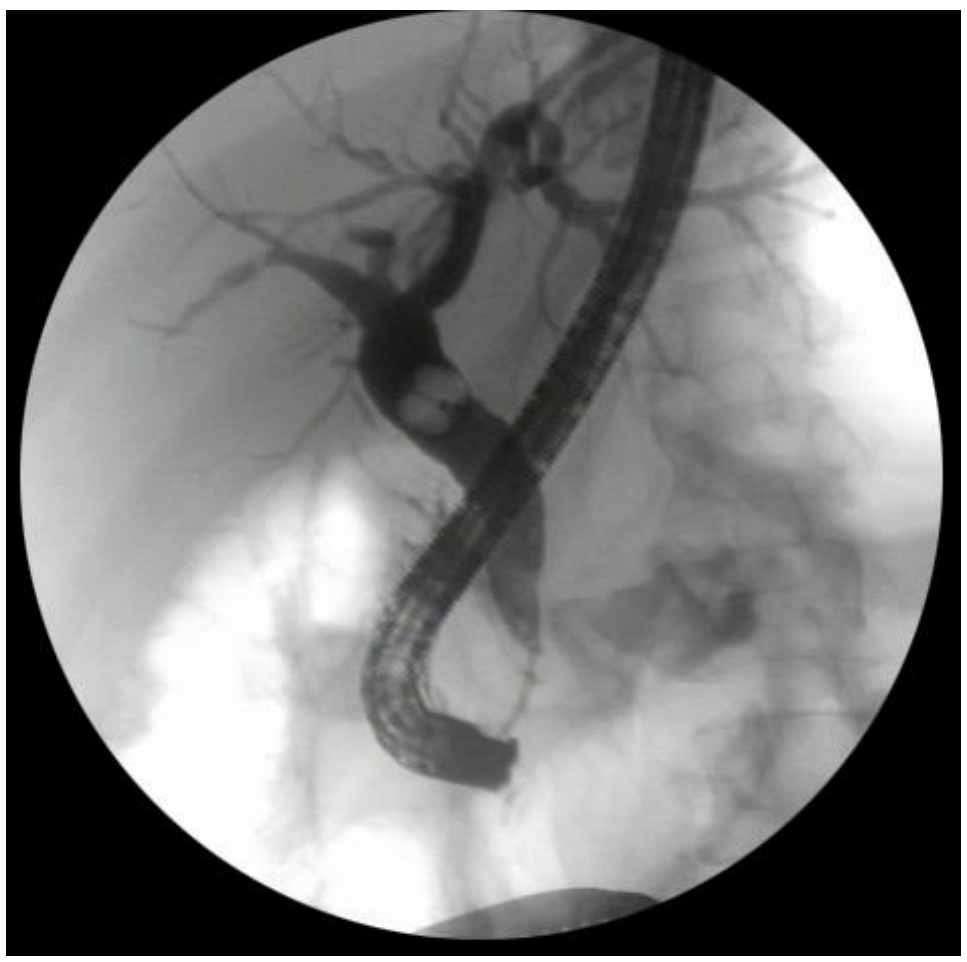

Figure 2. Fluoroscopic image during ERC showing dilated bile duct with an inflated stone extraction balloon inside

Before a biliary intervention can be performed (e.g. stone extraction or biliary stent insertion) the orifice of the papilla should be widened either by sphincterotomy or balloon dilatation. To perform an endoscopic sphincterotomy (EST) a deep cannulation inside the biliary tree with a guidewire should be accomplished and then the sphincterotomy can be achieved by using an ERCP sphincterotome over the inserted guidewire, by cutting the papilla in 11 O'clock direction, which is the normal anatomic position of the common bile duct (Jean Marc Canard, 2011).

Although successful selective biliary cannulation is a vital step in ERCP, it can fail in up to $5 \%-20 \%$ of cases using standard techniques. In such situations a precut sphincterotomy can be used, which has been associated with success rates approaching 100\% (Freeman \& Guda, 2005). A precut sphincterotomy is usually performed by using a needle knife, either by the freehand technique, where the cut is made starting at the orifice and extended upwards, or the fistulotomy technique, where the cut is made starting above the orifice and is extended downwards in direction of the orifice (Sundaralingam, Masson, \& Bourke, 2015). 


\subsubsection{Complications:}

All the negative outcomes that can be related to ERCP can be classified into complications, incidents, adverse events, and technical failure (Cotton, 1994; Cotton, Eisen, Aabakken, Baron, Hutter, Jacobson, Mergener, Nemcek, Petersen, Petrini, Pike, Rabeneck, Romagnuolo, \& Vargo, 2010; Cotton, Lehman, Vennes, Geenen, Russell, Meyers, Liguory, \& Nickl, 1991; Fleischer, 1994; Petersen, 2002):

- Complications: events that necessitate management by a physician and hospital admission or prolongation of the hospital stay.

- Incidents: Undesired events that do not fit the definition of complications.

- Adverse events: Adverse but inevitable outcomes of the procedure (e.g. loss of sphincter function after endoscopic sphincterotomy (EST)).

- Failure of the procedure

Complications related to ERCP can be classified into two main groups:

- General complications: which are common among all endoscopic procedures (e.g. allergic reaction to medications or to the contrast agent, respiratory depression, cardiovascular instability, and bleeding or perforation related to the passage of the endoscope.

- Selective complications: which are specific to ERCP and the instrumentation of the papilla and the pancreaticobiliary systems (e.g. post-ERCP pancreatitis, infection, bleeding and retroperitoneal duodenal perforation following endoscopic sphincterotomy).

A large spectrum of complications which can occur during or after ERCP as well as a grading system according to 1991 consensus panel are listed in Table 1and 2. (Cotton, Lehman, Vennes, Geenen, Russell, Meyers, Liguory, \& Nickl, 1991)

- Complications can be local (focal) at the site of contact with endoscope or instruments (e.g. perforation, bleeding, acute pancreatitis), or can be nonspecific when they occur in organs which have no direct connection to the procedure (e.g. cardiopulmonary problems) (Cotton, 1994).

- According to the timing of the complications, they ca be divided into early and late complications. The normal cutoff is at 30 days. The early complications include 
immediate, early and delayed complications which occur during the first 30 days after the procedure, while the late complications include related complications which occur after 30 days (Cotton, 1994).

- The severity of complications can be measured by the terms of length of hospital stay; blood transfusions; admission to an intensive care unit; the need for surgical, or endoscopic management, any related disability; and death (Cotton, 1994; Cotton, Lehman, Vennes, Geenen, Russell, Meyers, Liguory, \& Nickl, 1991; Fleischer, 1994; Petersen, 2002). 
Table 1. Classification of site, timing, and severity of complications related to endoscopic retrograde cholangiopancreatography (ERCP).

\begin{tabular}{|c|c|}
\hline \multicolumn{2}{|l|}{ Site } \\
\hline Focal & Occurring at the point of endoscopic contact \\
\hline Nonspecific & Occurring in organs not traversed or treated \\
\hline \multicolumn{2}{|l|}{ Timing } \\
\hline Immediate & Occurring during ERCP \\
\hline Early & Evident within the recovery period \\
\hline \multirow[t]{2}{*}{ Delayed } & Focal (occurring within 30 days) \\
\hline & Nonspecific (first symptom presenting within 3 days) \\
\hline Late & Evident after months or years \\
\hline \multicolumn{2}{|c|}{ Criteria for severity } \\
\hline \multicolumn{2}{|c|}{ Length of stay } \\
\hline Mild & $\leq 3$ nights \\
\hline Moderate & 4 to 10 nights \\
\hline Severe & >10 nights, intensive care unit (ICU)admission, or surgery \\
\hline Fatal & $\begin{array}{l}\text { Death attributable to the procedure within } 30 \text { days (or longer if under } \\
\text { continued in-patient treatment for the complication) }\end{array}$ \\
\hline \multicolumn{2}{|c|}{ Other indices of severity } \\
\hline \multicolumn{2}{|c|}{ Need for blood transfusion } \\
\hline \multicolumn{2}{|c|}{ Additional interventions (endoscopic or radiologic) } \\
\hline \multicolumn{2}{|c|}{ Total length of stay } \\
\hline Permanent & sidual disability \\
\hline
\end{tabular}


Table 2. Grading system for the major complications of endoscopic retrograde cholangiopancreatography (ERCP) and endoscopic sphincterotomy.

\begin{tabular}{|c|c|c|c|}
\hline & Mild & Moderate & Severe \\
\hline Pancreatitis & $\begin{array}{l}\text { Amylase at least three } \\
\text { times normal at more than } \\
24 \text { hours after the } \\
\text { procedure, requiring } \\
\text { admission or prolongation } \\
\text { of planned admission to } \\
\text { two to three days }\end{array}$ & $\begin{array}{l}\text { Hospitalization of } 4 \\
\text { to } 10 \text { days }\end{array}$ & $\begin{array}{l}\text { Hospitalization of } \\
\text { more than ten days, } \\
\text { hemorrhagic } \\
\text { pancreatitis, } \\
\text { phlegmon or } \\
\text { pseudocyst, } \\
\text { intervention } \\
\text { (percutaneous } \\
\text { drainage or surgery) }\end{array}$ \\
\hline Bleeding & $\begin{array}{l}\text { Clinical (not just } \\
\text { endoscopic) } \\
\text { bleeding, hemoglobin } \\
\text { drop }<3 \mathrm{~g} \text {, and no need for } \\
\text { transfusion }\end{array}$ & $\begin{array}{l}\text { Transfusion (four } \\
\text { units or less), no } \\
\text { angiographic } \\
\text { intervention } \\
\text { surgery }\end{array}$ & $\begin{array}{l}\text { Transfusion (five units } \\
\text { or more) or } \\
\text { intervention } \\
\text { (angiographic or } \\
\text { surgical) }\end{array}$ \\
\hline Cholangitis & $\begin{array}{l}\text { Temperature of }>38^{\circ} \mathrm{C} \text { for } \\
24 \text { to } 48 \text { hours }\end{array}$ & $\begin{array}{l}\text { Febrile or septic } \\
\text { illness requiring } \\
\text { more than three } \\
\text { days of hospital } \\
\text { treatment } \\
\text { endoscopic or } \\
\text { percutaneous } \\
\text { intervention }\end{array}$ & $\begin{array}{lll}\text { Septic shock or } \\
\text { surgery } & & \end{array}$ \\
\hline Perforation & $\begin{array}{l}\text { Possible, or only very } \\
\text { slight leak of fluid or } \\
\text { contrast, treatable by } \\
\text { fluids and suction for three } \\
\text { days or less }\end{array}$ & $\begin{array}{l}\text { Any definite } \\
\text { perforation treated } \\
\text { medically for } 4 \text { to } 10 \\
\text { days }\end{array}$ & $\begin{array}{l}\text { Medical treatment for } \\
\text { more than } 10 \text { days, or } \\
\text { intervention } \\
\text { (percutaneous or } \\
\text { surgical) }\end{array}$ \\
\hline
\end{tabular}

Incidence: The incidence of ERCP related complications is variable between different studies. These differences depend on the study design, selection of the patients, the used terminologies and the methods of data collection (Mallery, Baron, Dominitz, Goldstein, 
Hirota, Jacobson, Leighton, Raddawi, Varg, Waring, Fanelli, Wheeler-Harbough, Eisen, \& Faigel, 2003).

Many studies and meta-analyses have evaluated the incidence of ERCP related complications (Andriulli, Loperfido, Napolitano, Niro, Valvano, Spirito, Pilotto, \& Forlano, 2007; Freeman, Nelson, Sherman, Haber, Herman, Dorsher, Moore, Fennerty, Ryan, Shaw, Lande, \& Pheley, 1996; Williams, Taylor, Fairclough, Hamlyn, Logan, Martin, Riley, Veitch, Wilkinson, Williamson, \& Lombard, 2007):

- Specific complications related to ECRP including pancreatitis, hemorrhage, sepsis, and perforation totaled 1154/16.855 (6.9\%) in a meta-analysis included studies between 1987 and 2003, with mortalities of 55 cases (0.33 percent) (Andriulli, Loperfido, Napolitano, Niro, Valvano, Spirito, Pilotto, \& Forlano, 2007). Mild to moderate complications occurred in 872 cases (5.2\%), while severe complications occurred in 282 cases (1.7\%). In two later studies involving a total of 7252 patients, similar rates of specific complications (5.3 percent) and mortalities (0.34 percent) were documented (P. Wang, Li, Liu, Ren, Lu, Fan, Huang, Zhang, He, Sun, Zhao, Shi, Tian, Li, Li, \& Zhi, 2009; Williams, Taylor, Fairclough, Hamlyn, Logan, Martin, Riley, Veitch, Wilkinson, Williamson, \& Lombard, 2007).

- Nonspecific complications occurred in total of 173 (1.3\%) with mortality rate of $0.07 \%$ in a meta-analysis of 14 prospective studies and involving a total of 12,973 patients(Andriulli, Loperfido, Napolitano, Niro, Valvano, Spirito, Pilotto, \& Forlano, 2007). Similar rates were reported in two large prospective studies (P. Wang, Li, Liu, Ren, Lu, Fan, Huang, Zhang, He, Sun, Zhao, Shi, Tian, Li, Li, \& Zhi, 2009; Williams, Taylor, Fairclough, Hamlyn, Logan, Martin, Riley, Veitch, Wilkinson, Williamson, \& Lombard, 2007).

\section{Specific complications:}

Post-ERCP Pancreatitis is the most common complication related to ERCP. In a metaanalysis of 21 studies involving a total of 16,855 patients between 1987 and 2003, the rate of post-ERCP pancreatitis was 3.5\% (585 patients), while the incidence of severe pancreatitis was $0.4 \%$ (67 patients). Eighteen (0.11\%) mortalities were reported(Andriulli, Loperfido, Napolitano, Niro, Valvano, Spirito, Pilotto, \& Forlano, 2007) [25]. 
Bleeding can occur during or after ERCP and is usually related endoscopic sphincterotomy (EST). Similar to all endoscopic procedures a history of bleeding tendency or use of anticoagulants should be taken into consideration. A coagulation profile including prothrombin time and platelet count should be performed prior to the procedure. The incidence of post-ERCP bleeding was reported to be $1.3 \%$ (226 patients), in a review involving 21 studies and 16,855 patients, third of these cases had severe bleeding (Andriulli, Loperfido, Napolitano, Niro, Valvano, Spirito, Pilotto, \& Forlano, 2007).

Infections related ERCP procedure are most frequently occur during instrumentation of an obstructed biliary or pancreatic ducts. Post-ERCP infection is inevitable in some cases, even if a strict disinfection protocol has been followed. Therefore, the cornerstone of preventing post-ERCP infection is successful drainage of the obstructed duct (Aliperti, 1996). The incidence of cholangitis is reported to be 1.4 percent ( 0.2 percent were severe), with a procedure related mortality rate of 0.1 percent (Andriulli, Loperfido, Napolitano, Niro, Valvano, Spirito, Pilotto, \& Forlano, 2007).

Perforations can occur in $0.4 \%$ of cases, either due to direct trauma from the endoscope (esophagus, stomach and duodenum) or due to instrumentation of the papilla and pancreaticobiliary system (Vezakis, Fragulidis, \& Polydorou, 2015).

\subsection{Billroth II reconstruction}

\subsubsection{Historical Background}

Billroth II reconstruction is a surgical operation to restore the gastrointestinal continuity after a partial gastrectomy by performing a gastrojejunostomy. The first attempt to perform a gastroduodenostomy reconstruction was done by a Polish surgeon named Rydygier in 1881 ( $\mathrm{T}, 1881$ ) which was performed under chloroform anesthesia in a patient suffering from a peptic duodenal ulcer. However, the patient died during early recovery due to circulatory failure. In the same year Theodor Billroth, had successfully performed the first case of gastrojejujostomy in a patient suffering from gastric cancer (Pach, Orzel-Nowak, \& Scully, 2008). In 1885, Bilroth anastomosed the stomach (proximal to the tumor) to a jejunal loop in a patient suffering from gastric mass. In another step he resected the tumor and closed the cut ends of the stomach and the duodenum. This technique was later described as Billroth II partial gastrectomy (Santoro, 2005). In the following years, this procedure was modified by Mikulicz, Reichel, Polya, and Finsterer (Petri, 1985). 


\subsubsection{Indications}

The most common indication for Billroth II reconstruction is gastric outlet obstruction (GOO), which can be benign (e.g. complicated peptic ulcers) or malignant. Indications of BII include the following:

- Prepyloric or duodenal peptic ulcers complicated with GOO due to excessive scarring and narrowing of the pyloric area can be treated by vagotomy and antrectomy with the Billroth II reconstruction. The Bll reconstruction is also indicated for complicated ulcers not responding to medical therapy or when malignancy is suspected (Siu, Tang, Law, Chau, Yau, Yang, \& Li, 2004). Although it is rarely performed in recent years to treat the complications of peptic ulcer disease after development of the $\mathrm{H} 2$ blockers and the proton pump inhibitors, the Billroth II reconstruction is still commonly performed after distal gastric resection. Billroth II reconstruction can be carried out to manage some complications of peptic ulcer disease (e.g. perforation, bleeding, penetration, and strictures). It can also be performed to resect gastric carcinoma localized at the antrum.

- Post-corrosive stricture of antro-pyloric area with GOO due to acid ingestion.

- Resectable carcinoma of the antro-pyloric region is indicated for Bll where gastrojejunostomy is performed after radical subtotal gastrectomy. If the carcinoma is nonresectable a palliative gastrojejunostomy is indicated (Gurusamy, Kumar, \& Davidson, 2013; Stupart, Panieri, \& Dent, 2006).

- Selected cases with gastroparesis complicating diabetes mellitus or a previous gastric surgery, which is not responding to medical treatment or percutaneous gastrostomy, can be treated by performing a subtotal gastrectomy with gastrojejunostomy to relieve the symptoms.

\subsubsection{Contraindications}

Billroth II reconstruction is contraindicated in patients who are unfit for general anesthesia.

Relative contraindications of Billroth II reconstruction include the following: 
- Risk of anastomotic leakage (e.g. severe hypoalbuminemia or peritoneal metastasis with severe ascites)

- Severe peritonitis with severe sepsis (diffuse peritonitis alone is not a contraindication)

- Large gastric varices

- Laparoscopic approach in patients with a past history of operations in the upper abdomen (the presence of adhesions and the altered anatomy may complicate the procedure)

\subsubsection{Techniques}

The most commonly used incision is midline incision (from the xiphoid to the umbilicus). Additional exposure can be obtained by excising. The xiphoid can be excised and the extension can be extended downwards for extra exposure.

The Billroth II reconstruction is performed after doing partial gastrectomy by connecting the remnant part of the stomach to the proximal part of jejunum by an end-to-side anastomosis. Although the continuity of the jejunum will be preserved, the continuity of the duodenum will be sacrificed. It is used most frequently when a Billroth I reconstruction is not feasible, e.g. with extended distal gastrectomy. The afferent loop of the Billroth II reconstruction is coming from the duodenum while the efferent loop is extending distally (Houghton, Liepins, Clarke, \& Mason, 1996).

Two different techniques can be performed to accomplish the reconstruction: (Figure 3)

- The Hofmeister technique: In this technique the resection line on the lesser curvature side is closed, while the rest of the resection line on the greater curvature will be connected to the proximal part of the jejunum.

- The Polya technique: Here the entire length of the resection line will be directly anastomesed to the jejunum.

\subsubsection{Complications:}

The incidence of complications after Billroth II reconstruction has been markedly diminished in the last few decades due to the development and improvement of the technique. These complications can be classified into (Jex, van Heerden, Wolff, Ready, \& llstrup, 1987): 
Postoperative syndromes

- Secondary hemorrhage

- Leakage from the anastomosis

- Duodenal stump blowout

- Infection

- Anastomotic stricture

Postgastrectomy syndromes (secondary to gastric resection)

- Dumping syndrome

- Metabolic disturbances

- Colic

- Weight loss

Significant dumping syndrome with metabolic and cardiovascular manifestation occurs in up to $20 \%$ of patients after BII. Dumping syndrome is considered as the most common and disabling complication related to gastric resection after BII (Illingworth, 1960). It can present as abdominal cramps, bloating, diarrhea, palpitations, and lightheadedness.

Postgastrectomy syndromes (secondary to gastric reconstruction)

- Afferent loop syndrome

- Efferent loop syndrome

- Retained antrum syndrome

- Alkaline reflux gastritis

- Roux-en-Y stasis syndrome

Postvagotomy syndromes

In cases where vagotomy is performed, complications may include the following:

- Diarrhea

- Gastroparesis

- Incomplete vagal transaction 


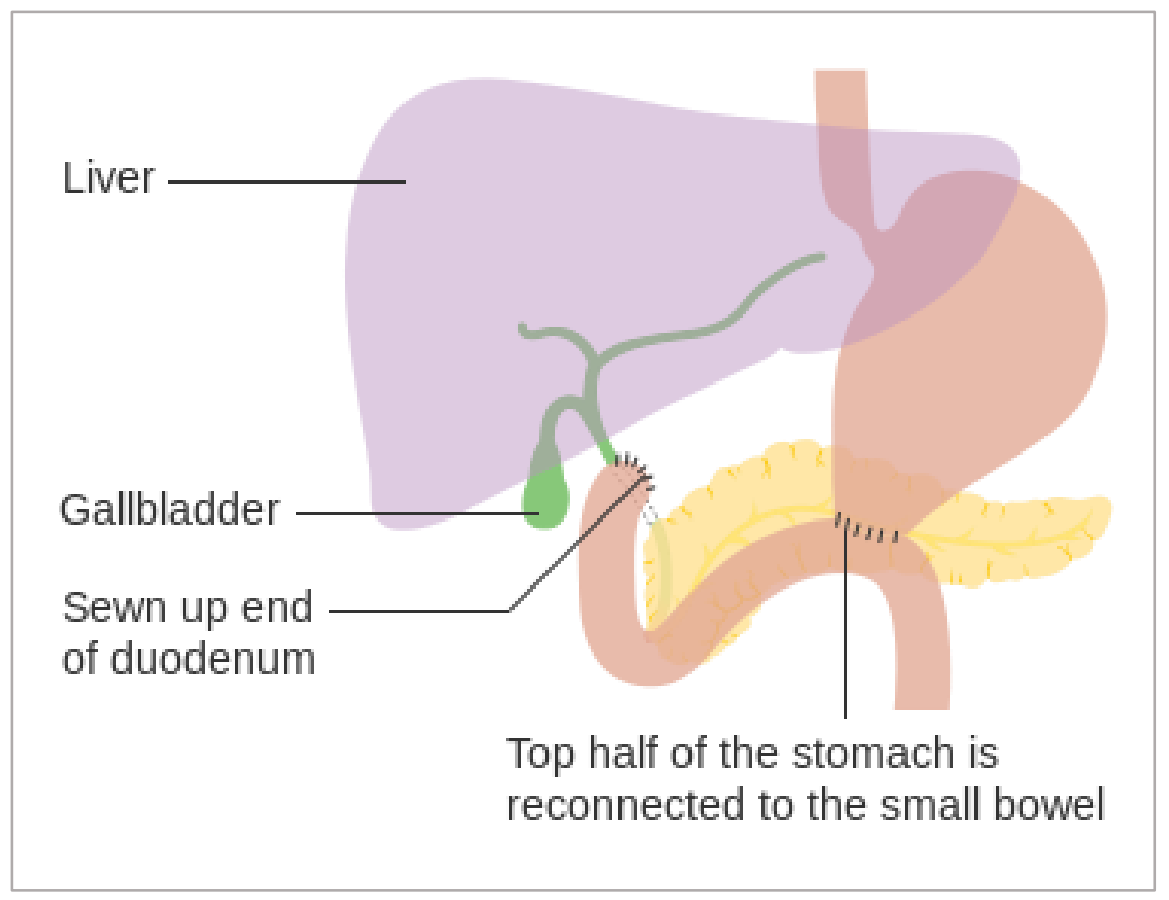

Figure 3. Illustration of Billroth II reconstruction consists

of an end-to-side gastrojejunal anastomosis (Cancer Research UK)

\subsection{ERCP challenges after Billroth II reconstruction}

\subsubsection{Background}

Because of the surgically altered anatomy, performing a diagnostic and/ or therapeutic endoscopic retrograde cholangiopancreatography after Billroth II reconstruction is more difficult and challenging compared to that with native anatomy (Bergman, van Berkel, Bruno, Fockens, Rauws, Tijssen, Tytgat, \& Huibregtse, 2001; Bove, Tringali, Familiari, Gigante, Boskoski, Perri, Mutignani, \& Costamagna, 2015; Lin, Siauw, Ho, \& Tung, 1999; Osnes, Rosseland, \& Aabakken, 1986).

In addition to BII reconstruction, there are other surgically altered anatomies that can make ERCP more difficult and challenging and increase the risk of complications. These situations might include:

- Roux-en-Y gastric bypass,

- Roux-en-Y gastric reconstruction 
- Roux-en-Y hepaticojejunostomy.

- Whipple Operation.

- Other bariatric surgeries.

The following issues should be taken into consideration by the endoscopist prior to performing an ERCP in patient with BII anatomy:

- Choosing the proper endoscope (side-viewing duodenoscope vs forward-viewing endoscope.

- Identifying and intubating the right loop, which should be the afferent loop.

- Getting to the duodenal stump in a retrograde approach.

- Cannulation of the major duodenal papilla, taking into consideration the inverted anatomy due to the retrograde approach.

- Finally, performing an endoscopic sphincterotomy.

These issues were raised by number of expert endoscopists shortly after the introduction of ERCP in the late sixties and EST in 1973(Urakami, 1973). However, a remarkable interest regarding this subject continued to grow and was addressed in many different studies, which will be discussed here (Aabakken, Holthe, Sandstad, Rosseland, \& Osnes, 1998; Demarquay, Dumas, Buckley, Conio, Zanaldi, Hastier, Caroli-Bosc, \& Delmont, 1998; Hintze, Adler, Veltzke, \& Abou-Rebyeh, 1997; Hintze, Veltzke, Adler, \& AbouRebyeh, 1997; Lin, Siauw, Ho, \& Tung, 1999). 


\subsubsection{Choice of the scope:}

Regarding the choice of the proper endoscope, it is still debatable. Some experts and studies would recommend the routine use of a forward-viewing endoscope, which is easier to handle and allows a better recognition and intubation of the afferent loop till reaching the duodenal stump. However forward-viewing endoscopes have major drawback which is the lack of a lever, making it more difficult to control the instruments which are needed to cannulate the papilla and to perform the EST (Y. G. Wang, Binmoeller, Seifert, Maydeo, \& Soehendra, 1996). On the other hand, most of the experts are recommending the use of side-viewing endoscopes to perform an endoscopic retrograde cholangiopancreatography in patients with Billroth II (BII) reconstruction, while they would reserve the forward-viewing endoscope to be used after a failed attempt with the duodenoscope (Feitoza \& Baron, 2001). In addition, forward-viewing endoscope is recommended as first choice for endoscopists with small experience (Byun, Kim, Sung, Jung, Jeon, Park, Kim, Kim, \& Baik, 2012). Other types of endoscopes can be used in situation of BII, which include:

- Oblique viewing endoscope: This endoscope combines the advantages of both forward-viewing endoscope and side-viewing duodenoscope which has an elevator to allow more control over the instruments, and an angle of view. These features render this oblique-viewing endoscopes as perfect tool for performing ERCP in patients with Billroth II reconstruction anatomy. Some Japanese studies have demonstrated a high success rate of ERCP in patients with prior BII reconstruction by using an oblique viewing endoscope (Kikuyama, Sasada, Matsuhashi, Ota, \& Nakahodo, 2009; Nakahara, Okuse, Suetani, Morita, Michikawa, Ozawa, Hosoya, Nomoto, Kobayashi, Otsubo, \& Itoh, 2015).

- Enteroscopy: Occasionally in some patients with prior Billroth II reconstruction, the afferent loop can be too long, rendering reaching the duodenal stump with forwardviewing endoscope and/or side-viewing endoscope impossible. In such situations, the use of enteroscopy (either single-balloon or double-balloon) has shown to be useful in multiple studies. Newly developed short single-balloon and doubleballoon with a wide working channel can achieve high success rates during ERCP in patients with BII anatomy (Dong, 2012; Okabe, Ishida, Kuraoka, Ushijima, \& Tsuruta, 2014). 


\subsubsection{Intubation of the afferent loop}

The papilla in the second part of the duodenum can be only reached through the afferent loop. For that reason, the first major challenge in Billroth II reconstruction is to identify and intubate the afferent loop and reach the papilla.

The loop on the lesser curve is usually examined first as it is more commonly will lead to the afferent limb. Use of fluoroscopy can be helpful and more accurate by directing the scope towards the right hypochondrium. Intubating the afferent loop can be very difficult and frustrating, especially when it is located on the lesser curve. Although the procedure usually starts while the patient lying in supine position, changing the patient position can improve the intubation of the afferent loop (Jean Marc Canard, 2011; Petter Cotton, 2005) (Figure 4).

If these methods fail, some tricks are available to facilitate the intubation of the afferent loop. The afferent loop can be intubated with Jagwire or stiff guidewire, followed by advancement of a 10 French biliary Soehendra dilator to make it more rigid and stable. Afterwards, the scope can be advanced over the dilator, which will function as a stabilizer and straightener, in to the afferent loop. The same method can be performed by using a biopsy forceps (Aabakken, Holthe, Sandstad, Rosseland, \& Osnes, 1998) or a snare (Lin, Siauw, Ho, \& Tung, 1999) which have also been reported but are mostly less effective and have higher risks. These methods should always be performed under fluoroscopic guidance to guarantee less risk of complications.

Another useful trick to intubate the afferent loop during the use of standard side-viewing duodenoscope, is the use of retrieval balloon enterography (Wu, Zhang, Gu, Zhao, Zhuang, Tao, Liu, \& Wang, 2014). After passing the guide wire in the afferent loop the retrieval balloon can be advanced and inflated. By injecting a contrast material the afferent loop can be fluoroscopically assed. By hooking the balloon deep in the afferent loop, the scope can advance.

Maneuvering the scope in the afferent loop is quite similar to conventional enteroscopy and colonoscopy. The scope will need to be straightened more than once during the procedure, and finally to obtain a good and stable position when the papilla is reached. Straightening of the scope is done either in clockwise or in anticlockwise direction depending on the shape and position of the loop. Keeping the scope in a short position 
will guarantee a better control and precise maneuvers during trials of cannulation of the papilla.

Turning the patient to the supine position can be necessary for radiological control. External hand compression to fix the loop, as performed during colonoscopy, can help advancing the scope. Injection of contrast agent or air inflation under radiological imaging can help to identify the right direction and the anatomy of the loops.

Cap assisted forward-viewing endoscope has shown in some studies to be advantageous during the ERCP in patients with prior Bll reconstruction by allowing better identification of the afferent loop. It also allowed better maneuvering around the acute angulations by providing a fixed distance between the jejunal wall and tip of the scope. In addition, the presence of the cap allowed easier cannulation of the papilla (Lee, 2004; Park, Lee, Joo, Kim, Choi, \& Rew, 2007).

\subsubsection{Cannulation of the papilla}

Because of the retrograde approach, when the papilla is reached, it will be located in an inverted position in comparison to a normal anatomy. The inverted anatomy of the papilla renders the selective cannulation of the bile duct more difficult and time consuming. Again, the choice of the scope would play a major role.

Because most of the ERCP catheters were developed with their tips curved upwards, most experts use a straight cannula to have a better axis toward the bile duct direction (5 to 6 o'clock, which is the opposite of the position in patients with unaltered anatomy).

The tip of the catheter can be bended to form a sigmoid shape, which can supposedly facilitate the cannulation. Fluoroscopy is mandatory to monitor every movement and manipulation, which can be, some time, more helpful than the endoscopic view. Presence of other anatomical anomalies like peripapillary diverticula may hinder cannulation, which is the same in the patient with normal anatomy.

As mentioned before, a side-viewing duodenoscope with a lever has the advantage of extra control over the accessories which allows a more precise manipulation of instruments.

Like in a standard ERCP technique in patients with normal anatomy, using a guidewire cannulation technique increases the success rate of deep cannulation of the biliary 
system, in comparison to contrast agent injection technique, in patients with prior Billroth II reconstruction (Tse, Yuan, Moayyedi, \& Leontiadis, 2013). A loop-tip wire can be used instead of convetional ERCP guidewire to achieve a selective cannulation in patients with Billroth reconstruction, as well as in difficult cannulation in patients with a normal anatomy (Chun, Kim, Moon, Lee, Lim, Park, Kang, Kim, Kang, \& Park, 2014). Unfortunately, limited data are available comparing success rate of cannulation by using different types of guidewire.

\subsubsection{Endosocopic sphincterotomy}

Finally, and if successful cannulation of the bile duct was achieved, performing endoscopic sphincterotomy is more challenging than in the situation of normal anatomy. The current standard sphincterotomes cut in the direction of 12 o'clock when used with a duodenoscope in normal anatomy, while in the situation of Billroth II reconstruction , sphincterotomy should be undertaken in the direction of 5 o'clock due to a reversed anatomy of the papilla as well as the common bile duct (Bergman, van Berkel, Bruno, Fockens, Rauws, Tijssen, Tytgat, \& Huibregtse, 2001).

For that purpose, different methods and accessories have been developed to facilitate endoscopic sphincterotomy in cases with Billroth II reconstruction. One of these techniques include the use of reverse sphincterotomes (e.g. Billroth II sphincterotome and $\mathrm{S}$-shaped sphincterotome) which are designed to cut in the direction of 5 o'clock. Another technique is performing a needle-knife sphincterotomy guided by a biliary endoprosthesis, which mandate an insertion of a small biliary stent $(5 \mathrm{Fr}$ ) prior to the cutting (Hintze, Veltzke, Adler, \& Abou-Rebyeh, 1997; van Buuren, Boender, Nix, \& van Blankenstein, 1995). To date, there is no standard technique to perform EST in postsurgical anatomy, and the choice of the method depends on operator preference (Prat, Fritsch, Choury, Meduri, Pelletier, \& Buffet, 1997). 


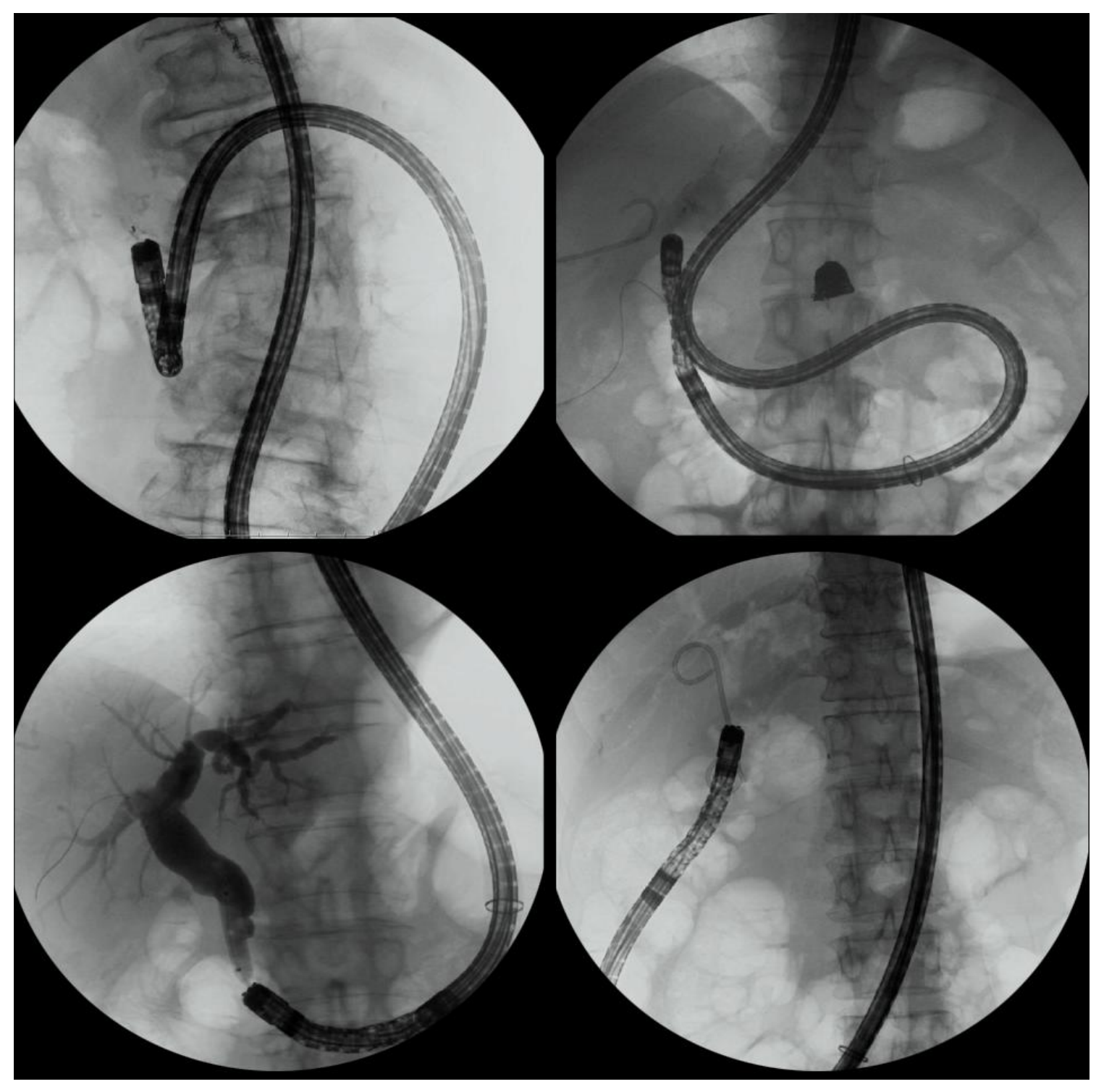

Figure 4. multiple fluoroscopic images for ERCP in Billroth II 


\subsection{Endoscopic Simulators}

\subsubsection{Types of simulators}

Since the description of the first endoscopic simulator in 1969 (Markman, 1969), simulation is widely used in endoscopic training and assessment, including upper and lower gastrointestinal endoscopy, endoscopic retrograde cholangiopancreatography and endoscopic ultrasound (Desilets, Banerjee, Barth, Kaul, Kethu, Pedrosa, Pfau, Tokar, Varadarajulu, Wang, Wong Kee Song, \& Rodriguez, 2011). Endoscopic simulators can be divided into three different categories, which are mechanical simulators, ex vivo animal platforms and virtual reality (VR) simulators (Jirapinyo, Kumar, \& Thompson, 2015; Martinek, Suchanek, Stefanova, Rotnaglova, Zavada, Strosova, \& Zavoral, 2011; Verdaasdonk, Stassen, Monteny, \& Dankelman, 2006). The VR simulators are costprohibitive and some studies showed poor discriminatory function for endoscopic skills (Ansell, Arnaoutakis, Goddard, Hawkes, Leicester, Dolwani, Torkington, \& Warren, 2013; Jirapinyo, Kumar, \& Thompson, 2015; McConnell, Kim, Ahmad, Falk, Forde, Ginsberg, Jaffe, Makar, Long, Panganamamula, \& Kochman, 2012). The ex vivo animal platforms need special animal use endoscopes, organ preparation, extensive setup and disposal processes (Jirapinyo, Kumar, \& Thompson, 2015). Other mechanical simulators have the advantage of being inexpensive and practical; however, most of them tend to allow performance of an entire procedure, rather than a specific technique and lack realism (Jirapinyo, Kumar, \& Thompson, 2015). Mechanical ERCP simulation models have been shown to be a useful tool for ex vivo evaluation of different accessories (Leung, Lee, Wilson, Lim, \& Leung, 2008). They provide standardized conditions for comparative analysis and are useful, when randomized clinical studies are hindered by low patient numbers. Although a variety of simulators were developed for ERCP, none of them has tackled the situation of ERCP in surgically altered anatomy (Bittner, Mellinger, Imam, Schade, \& Macfadyen, 2010; Frimberger, von Delius, Rosch, Karagianni, Schmid, \& Prinz, 2008; Katanuma, Itoi, Umeda, Tonozuka, Mukai, Yane, Kin, Matsumoto, Matsumori, Gon, Takaki, \& Tomonari, 2014; Leung, Lee, Rojany, Wilson, \& Leung, 2007; Matthes \& Cohen, 2006; Neumann, Mayer, Ell, Felzmann, Reingruber, Horbach, \& Hohenberger, 2000; Schneider \& Schepp, 2014). 


\subsubsection{Billroth II-ERCP simulator}

A recent study has reported the description and evaluation of the first mechanical model. This simulator is capable of simulating cannulation of the papilla as well as endoscopic sphincterotomy in Billroth II reconstruction. Different ERCP accessories can be used and both forward viewing endoscope as well as side viewing endoscope can be utilized with this simulator. Because of a transparent biliary system, which is made of glass, fluoroscopy is not needed to confirm the cannulation of the biliary system (Frimberger, Abdelhafez, Schmid, \& von Delius, 2016). 


\subsection{Problem statement and objectives}

Cannulation of the papilla and performing endoscopic sphincterotomy in patients with prior Billroth II reconstruction can be demanding even for experienced endoscopists. Although different endoscopic sphincterotomy techniques have been introduced during the last four decades to overcome this challenge, only few studies have been conducted on different techniques in Billroth II reconstruction. Many limitations were facing these studies because of the rarity and complexity of this condition. Those limitations include: the small sample sizes, the retrospective nature of the studies, and the absence of a comparative study design (Bergman, van Berkel, Bruno, Fockens, Rauws, Tijssen, Tytgat, \& Huibregtse, 2001). Furthermore, running a prospective study comparing different endoscopic techniques in real life practice would be unrealistic even in highly specialized centers. However, by using an appropriate endoscopic simulator these limitations can be overcome (Frimberger, Abdelhafez, Schmid, \& von Delius, 2016).

The aim of this study was to compare the efficacy of different endoscopic sphincterotomy techniques using the novel suitable mechanical simulator. We compared the use of a normal sphincterotome, a Billroth II sphincterotome, and a needle-knife endoscopic sphincterotomy guided by a biliary endoprosthesis. For each technique both a forwardviewing and a side viewing endoscope were used. The time needed for each technique was recorded and a score for the efficacy of the videotaped sphincterotomy was given by a blinded expert endoscopist. 


\section{Material and Methods}

\subsection{Study design}

This study was conducted during ERCP courses (GATE courses) which take place annually in Munich. These ERCP courses include hands on training, where different ERCP mechanical simulators are used. The EST techniques in this study were performed by 10 ERCP experts with Billroth II experience who supervised the training during different courses between 2011 and 2015 .

Each expert was allowed to perform 6 different EST techniques, by using the Bll simulator, in a random order. The duration needed for each technique was documented and the result of the sphincterotomy was video recorded. The video clips were then evaluated by a blinded expert and a score was given. Finally, we analyzed and compared the efficacy scores and durations of different techniques.

\subsection{The mechanical simulator}

The BII simulator is a further, newly developed component of a previously described ERCP simulation system (Frimberger, von Delius, Rosch, Karagianni, Schmid, \& Prinz, 2008). The Billroth II simulator system is a custom-made endosocopic mechanical simulator, which was designed and developed in a fine mechanical workshop in Munich, Germany. It allows the insertion of a side viewing duodenoscope and/or forward viewing endoscope, the cannulation of the papilla and the performance of sphincterotomy. The whole system weighs less than $3 \mathrm{Kg}$ and measures $28 \times 24 \times 5 \mathrm{~cm}$. The overall structure is made of aluminum and plastic. The system consists of a bended tube, which simulates the duodenum and the papilla, and an integrated see-through window which simulates the bile duct and the biliary tree. The duodenum is coated with a rubber material. The papilla is connected to the biliary system and is made of organic material which is earthed with a conventional cable to allow the current transmission for sphincterotomy purpose. The position of the papilla and the direction of the bile duct was carefully designed to simulate that of the reversed papilla in Billroth II situations which means towards 5 o'clock direction. After sphincterotomy the papilla can be exchanged with a new one in few seconds using an integrated sliding carriage. A front plastic plate contains a window exposing the biliary system, which is made of transparent plastic material, and that obviates the need for radiological control. 
Cannulation of the papilla is achieved by using a guide wire over ERCP catheter or sphincterotome. The system allows the insertion of a plastic stent $(5-10 \mathrm{Fr})$ as well as performing sphincterotomy using various accessories (e.g. needle knife, S-shape sphincterotome) and different techniques (cutting over a stent).

The system installation takes few Minutes, and can be mounted easily on an endoscopy trolley, preferably under the endoscopy monitor. It can also be mounted on any other bar (Figure 5 and 6).

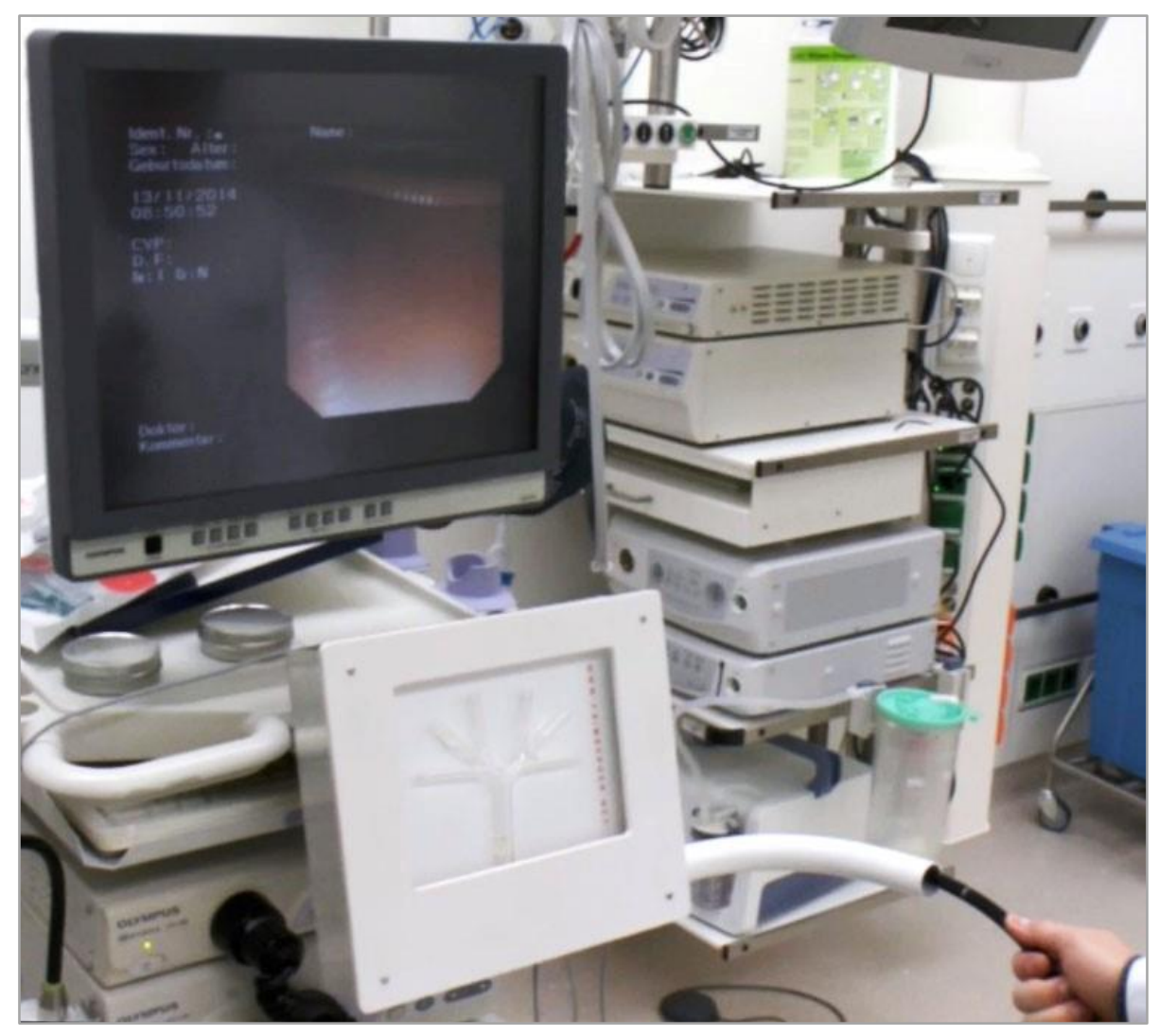

Figure 5. Billroth II simulator fixed on an endoscopy trolley below the monitor. In the window of the simulator a guidewire inserted through the papilla is visible. 


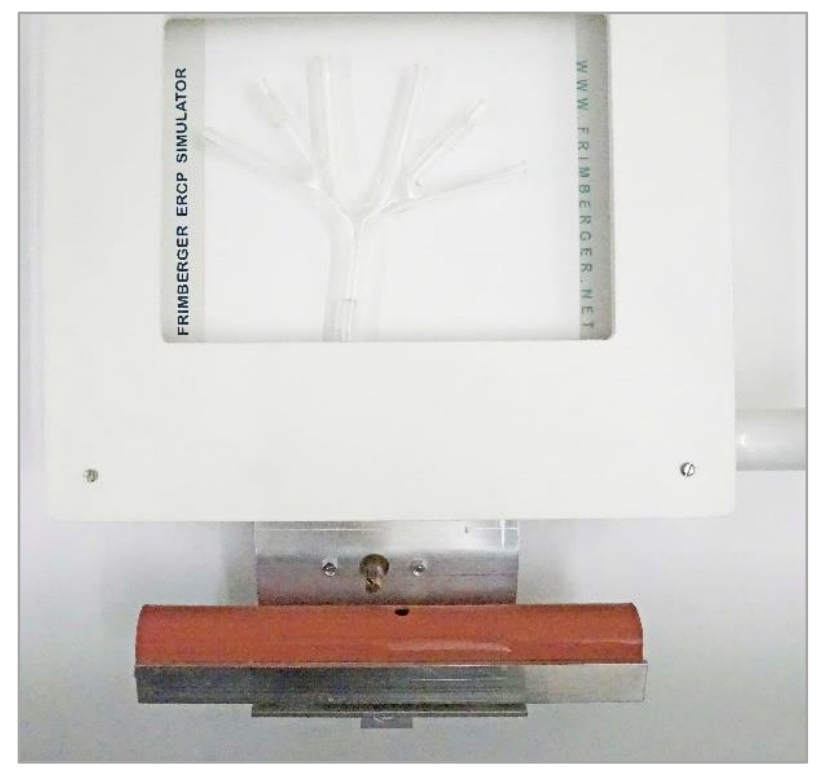

Figure 6. Billroth II simulator. The sliding carriage, which is otherwise not visible, is pulled out for insertion of the papilla. The duodenum is mounted onto the carriage. In the window, the transparent bile duct is visible.

When the endoscope is introduced into the simulator, after having passed the curved intubation tube, it reaches the duodenum with the papilla. Instruments introduced into and beyond the papilla become visible in the transparent bile duct in the window of the simulator. For fixing the papilla, a sliding carriage is pulled down with a lever at the bottom of the simulator (Figure. 7). The papilla consists of a metal spring embedded into the organic part of the papilla (Figure. 8). Both the papilla and the metal spring have a canal through which inserted instruments can easily pass. The papilla is fixed by pressing the spiral into the groove of the mount and can be easily removed again (Figure. 9). The total length of the organic part of the papilla is $19 \mathrm{~mm}$. The portion of the papilla protruding into the duodenum is adjustable according to the purpose of the given training. A far protruding papilla, e.g. $14 \mathrm{~mm}$, offers the trainee a large surface for practicing needle knife cuts. The length is adjusted by varying the fixation point of the metal spring to the mount. The evolution of the papilla, influenced by course experiences, resulted in them being easily intubated if done carefully. If approached inappropriately, not in line with its axis, the papilla is perforated, which is corresponding to unsuccessful cannulation attempts in a patient. If the introduced guidewire does not appear in the window showing the bile duct, it indicates an inadequate technique. 


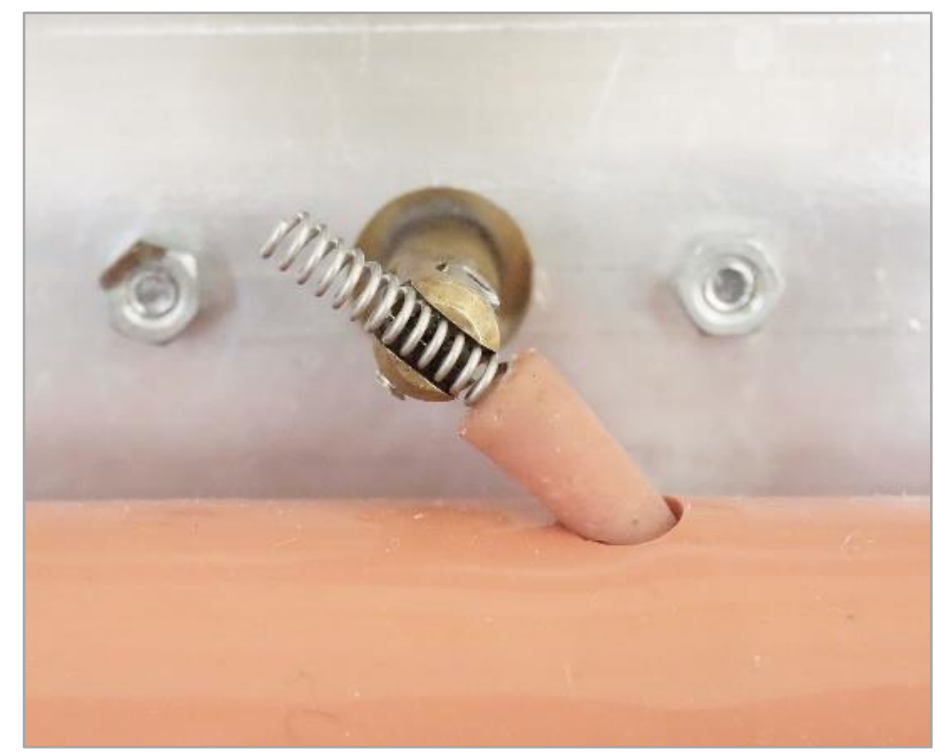

Figure 7. The papilla is inserted into the opening of duodenum and fixed to the mount by gently pressing its metal coil into the groove of the mount. The metal coil serves for grounding the papilla via the mount connected to a socket at the back. When the carriage is closed, the coil leads instruments inserted into the papilla into the bile duct.

This can be viewed in the window of the simulator.

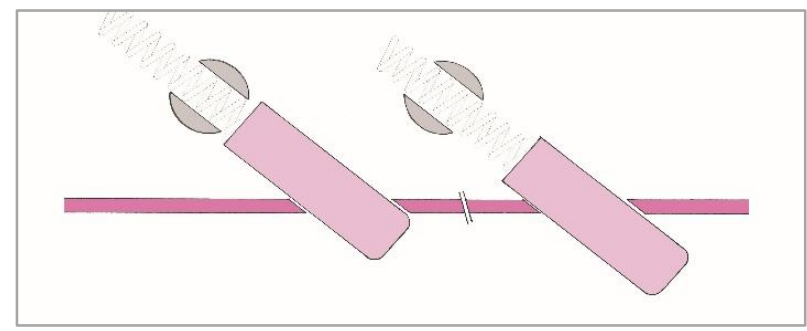

Figure 8. The working length of the papilla, that is the portion protruding into the duodenum, is adjustable according to the purpose of the given training. The working length is adjusted by varying the fixation point of the metal spring to the mount. On the left, a short portion of the papilla is visible inside the duodenum. A far protruding papilla (right) allows the trainee to practice a longer cut than in reality. This gives them a better opportunity to learn the handling of the sphincterotomes in combination with the application of HF current.

The construction validity of this mechanical simulation model has recently been reported in detail (Frimberger, Abdelhafez, Schmid, \& von Delius, 2016).

\subsection{Expert participant}

Ten ERCP experts participated in this study. All the experts participated as trainers in the ERCP courses. A participant was considered as an expert and thus can be included in the 
study if he had performed a minimum of 1000 ERCP examinations including at least 10 cases of Billroth II anatomy. If the participant fulfilled the inclusion criteria, the study design and the aims were explained to him and then he was asked to take part in it.

The participants had a mean ERCP experience of 17 years (standard deviation 8 years) with a mean of 147 cases of ERCP in postsurgical anatomy (standard deviation 232 cases). None of the participants had used the Billroth simulator before this study.

\subsection{Endoscopic Sphincterotomy techniques and equipment}

In this study, we evaluated and compared six different endoscopic sphincterotomy techniques as follows (Figures 9 and 10):

1) wire-guided standard sphincterotome (PreCurved Double Lumen Sphinterotome, Cook Medical, Limerick, Ireland) endoscopic sphincterotomy using a side-viewing endoscope (TJF-160VR, Olympus, Germany), In this technique, by using a side-viewing endoscope, a guide wire was first inserted in the bile duct and then a standard sphincterotome was used to perform the EST.

2) wire-guided BII sphincterotome (Billroth II Sphincterotome, Cook Medical, Limerick, Ireland) endoscopic sphincterotomy using a side-viewing endoscope (TJF-160VR). In this technique, by using a side-viewing endoscope, an EST was performed by using a B II sphincterotome, after cannulation of the bile duct with a guide wire.

3) needle-knife (Huibregtse Triple Lumen Needle Knife, Cook Medical, Limerick, Ireland) endoscopic sphincterotomy guided by biliary endoprosthesis using a side-viewing endoscope (TJF-160VR). Here, the EST was performed using a side-viewing endoscope in three steps: i) cannulation of the bile duct with a guide wire, ii) insertion of a biliary stent, iii) cutting the papilla with a needle knife, where the biliary stent was used as a guidance.

4) wire-guided standard sphincterotome (PreCurved Double Lumen Sphinterotome, Cook Medical) endoscopic sphincterotomy using a forward-viewing endoscope (PCF-180AI, Olympus, Germany). In this technique, by using a forward-viewing endoscope, a guide wire was first inserted in the bile duct and then a standard sphincterotome was used to perform the EST.

5) wire-guided BII sphincterotome (Billroth II Sphincterotome, Cook Medical, Limerick, Ireland) endoscopic sphincterotomy using a forward-viewing endoscope (PCF-180AI). In 
this technique, by using a forward-viewing endoscope, an EST was performed by using a B II sphincterotome, after cannulation of the bile duct with a guide wire.

6) needle-knife (Huibregtse Triple Lumen Needle Knife, Cook Medical) EST guided by biliary endoprosthesis (5 F Stent) using a forward-viewing endoscope (PCF-180AI). Here, the EST was performed using a side-viewing endoscope in three steps: i) cannulation of the bile duct with a guide wire, ii) insertion of a biliary stent, iii) cutting the papilla with a needle knife, where the biliary stent was used as a guidance.

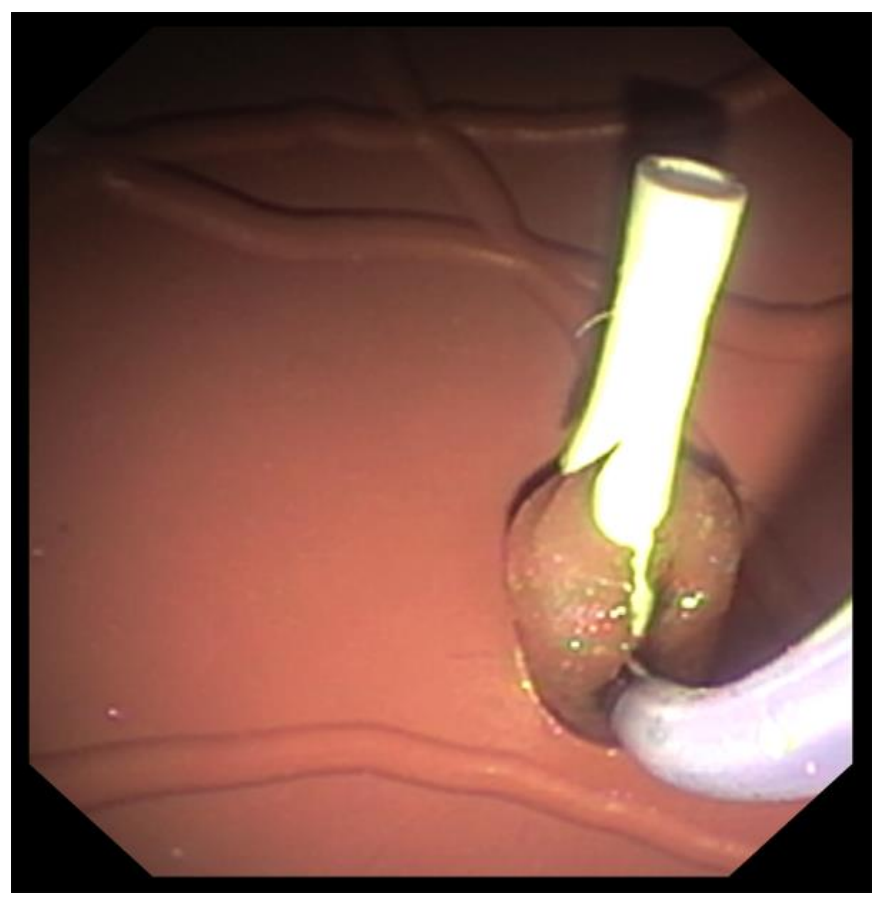

Figure 9. Endoscopic view of endoscopic sphincterotomy using needle knife guided by endoprosthesis and a side-viewing endoscope (technique no. 3). 


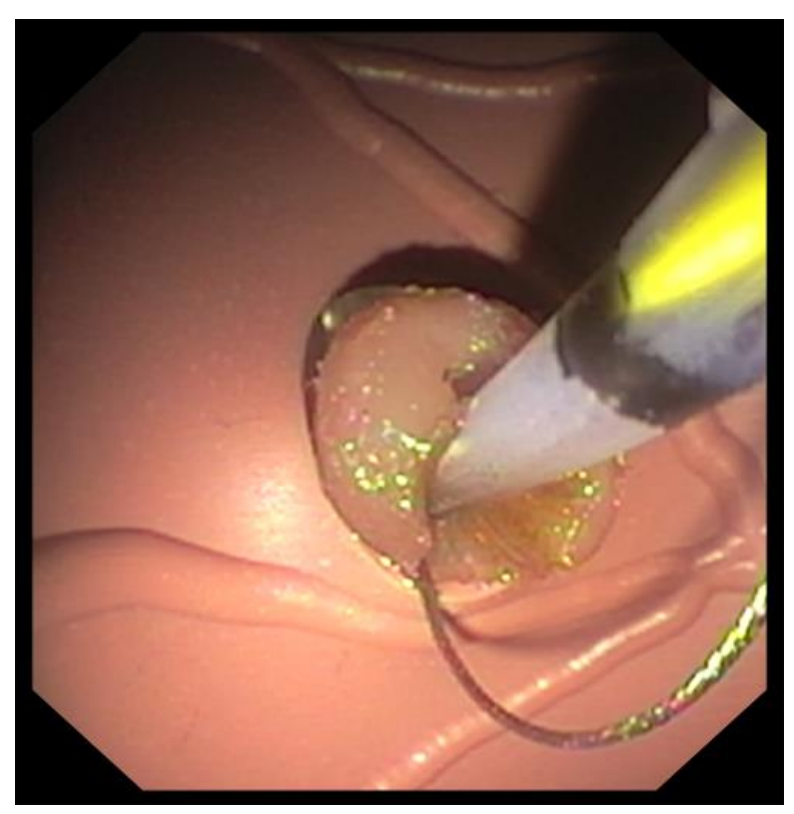

Figure 10. Endoscopic view of endoscopic sphincterotomy using Billroth II sphincterotome and a forward-viewing endoscope (technique no. 4).

In techniques number 1, 2, 4 and 5 the papilla was directly cannulated using a wire with a hydrophilic tip (Jagwire, Boston Scientific, U.S) and the respective sphincterotome followed by endoscopic sphincterotomy with the use of a electrosurgical generator (VIO 300D , Erbe Elektromedizin, Tübingen, Germany).

In techniques number 3 and 6 cannulations of the papilla was done using a wire (Jagwire) and an ERCP catheter (Contour ERCP Cannula, Boston Scientific, Marlborough, USA). The catheter was then withdrawn and a 5 Fr Stent (Peter Pflugbeil GmbH, Germany) inserted into the papilla. Afterwards the endoscopic sphincterotomy was performed using the needle-knife.

\subsection{Procedures}

After accepting to participate in the study, the study design and the outcome variables were explained to each participant.

Each of the 10 participants answered a questionnaire about his endoscopic experience, ERCP experience in normal anatomy and BII anatomy, and his preferred endoscopic sphincterotomy technique in the setting of Billroth II. 
After that, each participant received an orientation including explanation and inspection of the simulators. Moreover, they were informed in detail about the six different EST techniques which will be evaluated in the study.

Afterwards, each participant was asked to perform the six endoscopic sphincterotomy procedures in a randomized order, using the above-mentioned techniques. Time was recorded for every procedure starting with intubation of the simulator with the endoscope and stopping at completion of the endoscopic sphincterotomy. An endoscopic video of the cut papilla was recorded after the end of every procedure to be used for the evaluation of the efficacy of the endoscopic sphincterotomy.

\subsection{Blinded evaluation of ESTs and the efficacy score}

Each videotape was digitally converted and recorded in MPEG-2 format for evaluation by an expert external reviewer. The reviewer had performed more than 5000 ERCPs including more than 30 ESTs in patients with postsurgical anatomy. The reviewer had not participated in any of the previous steps of this study and was blinded to participant and technique data. Video clips were randomly rearranged before the evaluation.

Each examination was given an efficacy score on a 10-point numeric rating scale (0 completely unsuccessful, 1 very poor, 10 excellent) regarding the direction of cutting, length of the cutting and presence or absence of hesitation marks.

An excellent direction of cutting was considered as 5-6 o'clock direction. A perfect length of cutting was from the orifice of the papilla till just above the duodenal wall. Hesitation marks were defined as any other cut apart from the complete endoscopic sphincterotomy.

\subsection{Outcome Variables and Data analysis}

The primary outcome of this study was to compare the efficacy scores among the different sphincterotomy techniques. Secondary end-point was to compare the duration needed to complete each technique.

Data are described by mean \pm standard deviation and are visualized by boxplots overlaid with individually observed data. A repeated measurement ANOVA was performed to compare the main effects of endoscope type and cutting technique as well as their interaction. A level of significance of $5 \%$ was used for each test. 


\section{$3 \quad$ Results}

In this study, we compared 6 different endoscopic sphincterotomy techniques in Billroth II anatomy by using a novel validated mechanical simulator. Ten ECRP experts participated in this study. Each participant performed the six different techniques in a random order. For each case, duration was documented and a video for the final EST was recorded. A total of 60 videos (one video per case) were collected and evaluated by a blinded external expert reviewer. An efficacy score was given for each EST. The efficacy scores as well as the durations were compared.

\subsection{Participant experience and preference}

The endoscopic experiences of the participants are represented in Table 3.

\section{Table 3: The endoscopic experience of the participants}

\begin{tabular}{|c|c|c|c|c|}
\hline Participant & $\begin{array}{c}\text { Years of endoscopic } \\
\text { experience }\end{array}$ & $\begin{array}{c}\text { Years of ERCP } \\
\text { experience }\end{array}$ & $\begin{array}{c}\text { Total no. of } \\
\text { ERCPs }\end{array}$ & $\begin{array}{c}\text { Total no. of } \\
\text { ERCPs in BII }\end{array}$ \\
\hline 1 & 12 & 8 & 1200 & 10 \\
\hline 2 & 15 & 11 & 4000 & 30 \\
\hline 3 & 20 & 17 & 12000 & 60 \\
\hline 4 & 18 & 16 & 4000 & 30 \\
\hline 5 & 30 & 26 & 6000 & 100 \\
\hline 6 & 15 & 12 & 1000 & 30 \\
\hline 7 & 25 & 22 & 8000 & 75 \\
\hline 8 & 34 & 25 & 3000 & 30 \\
\hline 9 & 31 & 31 & 20000 & 800 \\
\hline 10 & 6 & 5 & 2020 & 30 \\
\hline
\end{tabular}

The participants had a mean ERCP experience of 17 years (standard deviation 8 years) with a mean of 147 cases of ERCP in BII anatomy (standard deviation 232 cases). 
Five participants were preferring needle-knife endoscopic sphincterotomy guided by endoprosthesis, three were preferring Billroth II sphincterotome, one was preferring standard sphincterotome and one was preferring balloon dilatation.

\subsection{Efficacy score}

\subsubsection{Overview of efficacy scores}

The mean and standard deviation for the efficacy of the different endoscopic sphincterotomy techniques using side- and forward-viewing endoscopes are illustrated in Table 4. The minimum, maximum, interquartile range and median are illustrated in Figure 11.

Table 4. Efficacy of endoscopic sphincterotomy. Blinded videotapes of cut papillae were rated by an ERCP expert on a numeric rating scale.

\begin{tabular}{|c|c|c|c|}
\hline & $\begin{array}{c}\text { Standard } \\
\text { sphincterotome }\end{array}$ & Bll sphincterotome* & $\begin{array}{c}\text { Needle knife } \\
\text { guided by } \\
\text { endoprosthesis }\end{array}$ \\
\hline $\begin{array}{c}\text { Side-viewing } \\
\text { endoscope }\end{array}$ & $2.2 \pm 3.0$ & $6.3 \pm 2.8$ & $8.9 \pm 1.5$ \\
\hline $\begin{array}{c}\text { Forward-viewing } \\
\text { endoscope }\end{array}$ & $3.2 \pm 2.7$ & $6.4 \pm 2.8$ & $8.0 \pm 1.6$ \\
\hline
\end{tabular}

0 completely unsuccessful, 1 very poor, 10 excellent; mean \pm standard deviation.

${ }^{* *}$ Needle knife guided by an endoprosthesis was rated significantly superior to both the Bll sphincterotome $(p=0.017)$ and the standard sphincterotome $(p<0.001)$, whereas the *Bll sphincterotome was significantly superior to the standard sphincterotome $(p=0.001)$. 


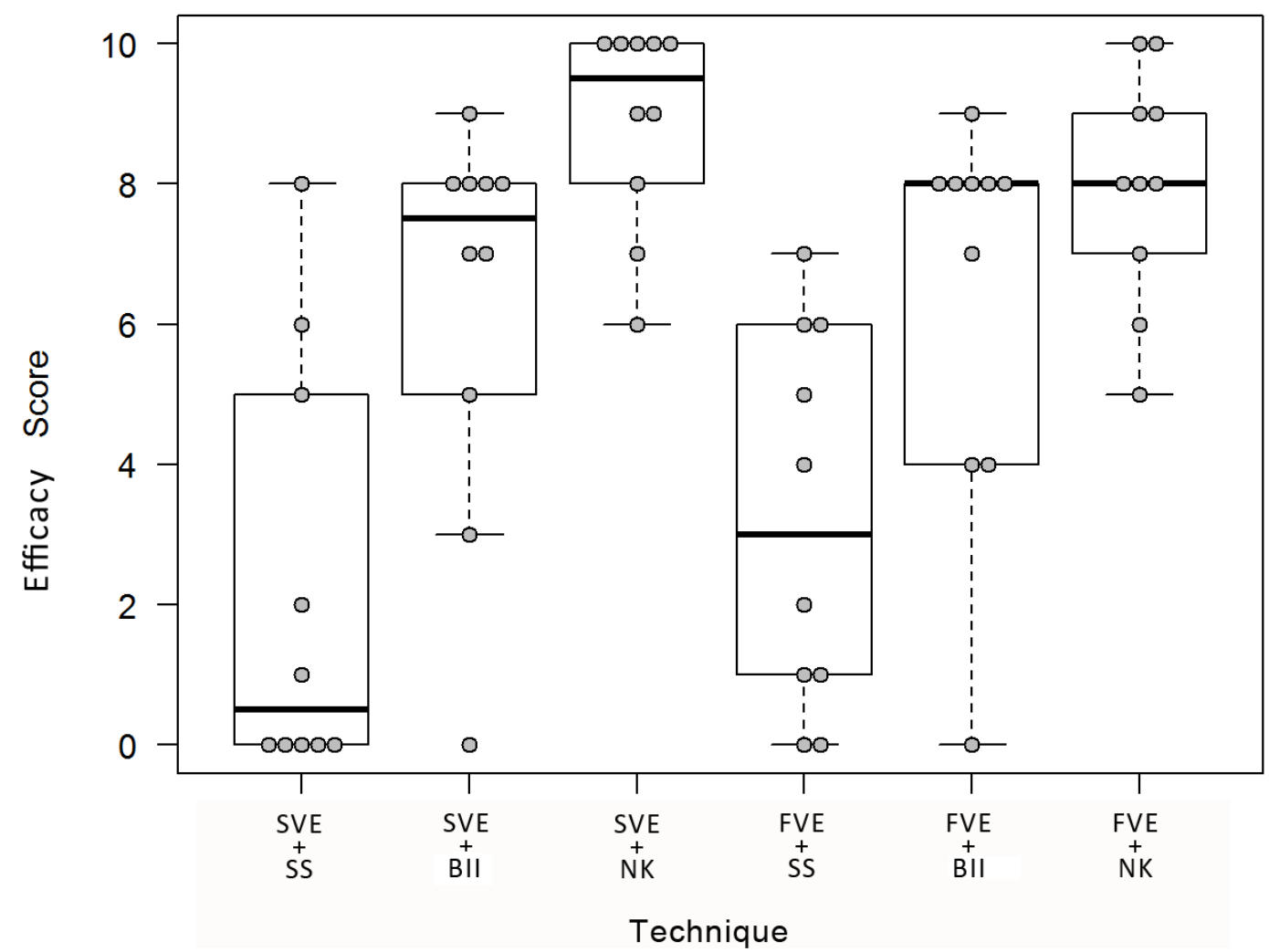

Figure 11. Box-Plot shows the minimum, maximum, interquartile range and median value of efficacy of EST using different techniques. (0 completely unsuccessful, 1 very poor, 10 excellent; SVE = side-viewing duodenoscope, FVE = forward-viewing endoscope, $S S=$ standard sphincterotome, $B I I=B I I$ sphincterotome, $N K=$ needle-Knife EST guided by endoprosthesis).

The standard sphincterotome gathered efficacy scores of $2.2 \pm 3.0$ and $3.2 \pm 2.7$ by using side-viewing endoscope and forward-viewing endoscope respectively. The Billroth II sphincterotome gathered efficacy scores of $6.3 \pm 2.8$ and $6.4 \pm 2.8$ by using side-viewing endoscope and forward-viewing endoscope respectively. The needle knife guided by end endoprosthesis gathered efficacy scores of $8.9 \pm 1.5$ and $8.0 \pm 1.6$ by using side-viewing endoscope and forward-viewing endoscope respectively.

\subsubsection{Effect of type of the scope}

There was no significant difference between the efficacy scores when forward-viewing endoscope or side-viewing endoscope was used $(p=0.910)$. 


\subsubsection{Comparison of different EST techniques}

Analysis of the three different endoscopic sphincterotomy techniques irrespective to the type of the endoscope showed a significant difference in the efficacy of the endoscopic sphincterotomy between the three cutting techniques $(p<0.001)$.

By comparing the cutting score of the three different techniques irrespective to the type of the endoscope, the needle knife guided by an endoprosthesis was rated significantly superior to both the Billroth II sphincterotome $(p=0.017)$ and the standard sphincterotome $(p<0.001)$, whereas the Billroth II sphincterotome was significantly superior to the standard sphincterotome $(p=0.001)$. There was no significant interaction between the endoscope types and the techniques $(p=0.238)$ regarding the efficacy score.

\subsection{Duration}

The mean and standard deviation for both efficacy and duration for different endoscopic sphincterotomy techniques using side- and forward-viewing endoscopes are illustrated in Table 5. The minimum, maximum, interquartile range and median are illustrated in Figure 12.

Table 5. Time consumption (sec) of endoscopic sphincterotomy techniques calculated from the start with intubation of the simulator with the endoscope until the completion of the endoscopic sphincterotomy.

\begin{tabular}{|c|c|c|c|}
\hline & $\begin{array}{c}\text { Standard } \\
\text { sphincterotome }\end{array}$ & Bll sphincterotome & $\begin{array}{c}\text { Needle knife } \\
\text { guided by } \\
\text { endoprosthesis }\end{array}$ \\
\hline Side-viewing endoscope & $249.8 \pm 105.9$ & $163.5 \pm 80.7$ & $243.4 \pm 37.8$ \\
\hline $\begin{array}{c}\text { Forward-viewing } \\
\text { endoscope }\end{array}$ & $262.6 \pm 131.1$ & $165.2 \pm 72.0$ & $294.9 \pm 107.4$ \\
\hline
\end{tabular}

Mean \pm standard deviation.

${ }^{* *}$ BII sphincterotome had significantly shorter time consumption than both the standard sphincterotome $(p=0.004)$, and the needle knife EST guided by an endoprosthesis $(p=0.005)$.

The standard sphincterotome had durations of $249.8 \pm 105.9$ and $262.6 \pm 131.1$ by using side-viewing endoscope and forward-viewing endoscope respectively. The Billroth II sphincterotome had durations of $163.5 \pm 80.7$ and $165.2 \pm 72.0$ by using side-viewing 
endoscope and forward-viewing endoscope respectively. The needle knife guided by end endoprosthesis had durations of $243.4 \pm 37.8$ and $294.9 \pm 107.4$ by using side-viewing endoscope and forward-viewing endoscope respectively.

There was no significant difference between the durations when forward-viewing endoscope or side-viewing endoscope was used $(p=0.219)$. By comparing the duration of the three different techniques irrespective to the type of the endoscope, using ANOVA and Post Hoc tests, the Bll sphincterotome had significantly shorter time consumption than both the standard sphincterotome $(p=0.004)$, and the needle knife endoscopic sphincterotomy guided by an endoprosthesis $(p=0.005)$. There was no significant difference in duration between the needle knife endoscopic sphincterotomy guided by an endoprosthesis and standard sphincterotome $(p=0.770)$. There was no significant interaction between the examiners and the technique regarding the duration $(p=0.48)$. 


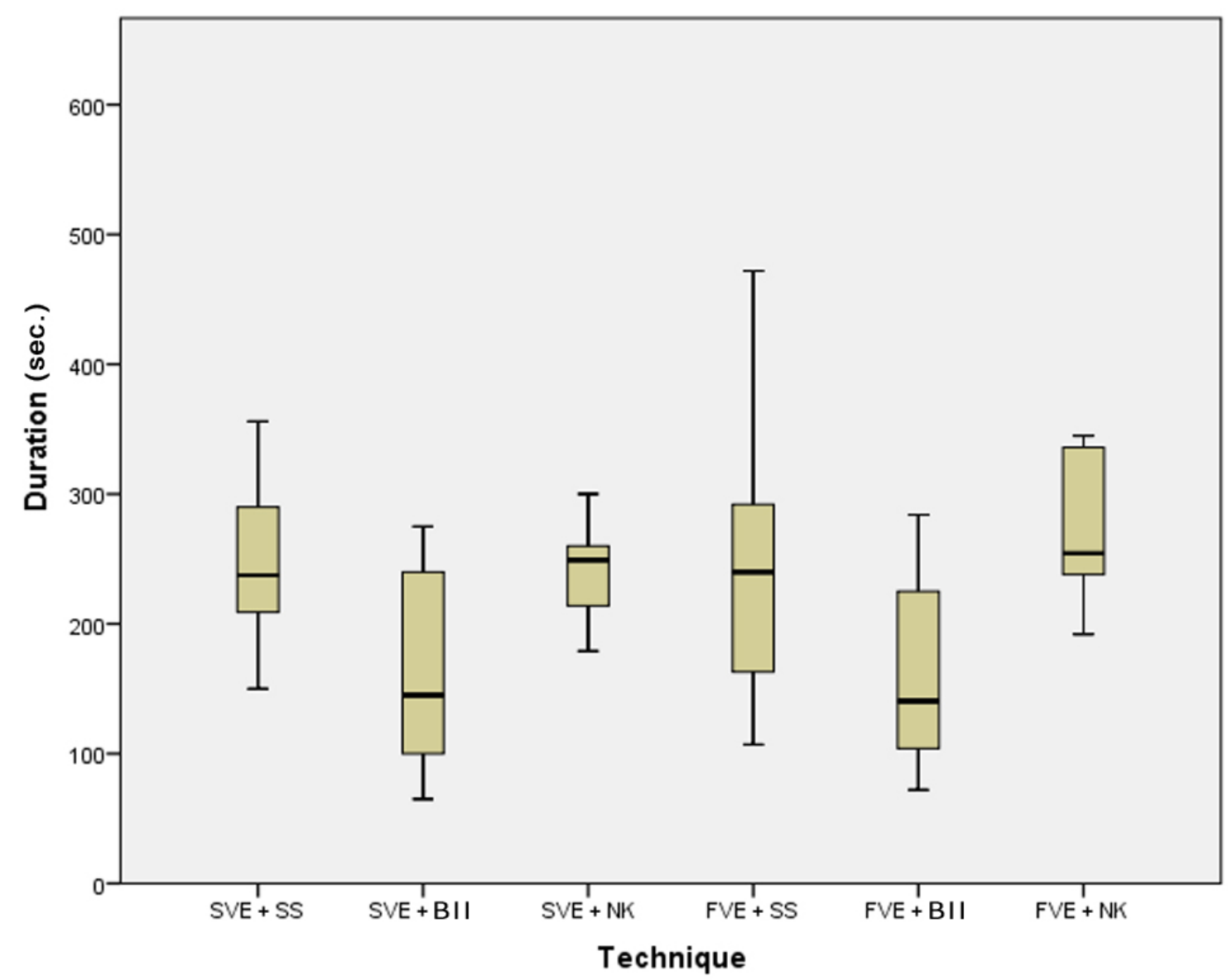

Figure 12. Box-Plot shows the minimum, maximum, interquartile range and median value of duration of EST using different techniques (sec). (SVE = side-viewing endoscope, FVE = forward-viewing endoscope, SS = standard sphincterotome, BII = BII sphincterotome, NK = needle-Knife EST guided by endoprosthesis. 


\section{Discussion}

Indications for ERCP with prior Billroth II gastrectomy are numerous (Table 6) (Bove, Tringali, Familiari, Gigante, Boskoski, Perri, Mutignani, \& Costamagna, 2015). ERCP after Billroth II reconstruction is challenging (Baron, Petersen, Mergener, Chak, Cohen, Deal, Hoffinan, Jacobson, Petrini, Safdi, Faigel, Pike, \& Endoscopy, 2006). One of the major difficulties having reached the papillary region, in a retrograde approach, with the endoscope is the ability to cannulate and cut the endoscopically inversely oriented papilla (Moreels, 2014). Cannulation of the papilla and performing endoscopic sphincterotomy in patients with prior Billroth II reconstruction can be demanding even for experienced endoscopists. Different endoscopic sphincterotomy techniques have been introduced during the last four decades to overcome this challenge. However, only few studies have been conducted on different sphincterotomy techniques in Billroth II reconstruction. Many limitations were facing these studies because of the rarity and complexity of this condition. Those limitations include: the small sample sizes, the retrospective nature of the studies, and the absence of a comparative study design (Bergman, van Berkel, Bruno, Fockens, Rauws, Tijssen, Tytgat, \& Huibregtse, 2001).

\section{Table 6: Indications of ERCP in patients with prior Billroth II gastrectomy}

\begin{tabular}{|l|}
\hline Common bile duct stones \\
\hline Obstructive jaundice \\
\hline Acute cholangitis \\
\hline Chronic pancreatitis \\
\hline Acute biliary pancreatitis \\
\hline Benign biliary strictures \\
\hline Malignant biliary strictures \\
\hline Pancreatic head tumors \\
\hline
\end{tabular}

Furthermore, running a prospective study comparing different endoscopic sphincterotomy techniques in real life practice would be unrealistic even in highly specialized centers, taking into consideration the scantiness of the disease. However, and as a good alternative, using an appropriate endoscopic simulator these limitations can be overcome. 
Several mechanical ERCP simulators have been described in the literature (Table 7). Nevertheless, they are all limited to cannulation and sphincterotomy in the setting of normal anatomy. The simulator used in this study was specially developed to simulate the anatomy after Billroth II reconstruction and it has shown favorable outcome in a previous study by trainees and experts evaluating the realism, the cannulation of the papilla and endoscopic sphincterotomy in the setting of Billroth II reconstruction (Frimberger, Abdelhafez, Schmid, \& von Delius, 2016).

Table 7. Comparison of different mechanical ERCP simulation models.

\begin{tabular}{|l|l|l|l|l|l|}
\hline $\begin{array}{l}\text { Study first } \\
\text { author, } \\
\text { year }\end{array}$ & Construction & $\begin{array}{l}\text { Orientation of } \\
\text { the papilla }\end{array}$ & Sphincterotomy & $\begin{array}{l}\text { Simulation } \\
\text { of } \\
\text { pancreatob } \\
\text { iliary } \\
\text { system }\end{array}$ & $\begin{array}{l}\text { Need for } \\
\text { fluoroscopy }\end{array}$ \\
\hline $\begin{array}{c}\text { Leung } \\
2007^{10}\end{array}$ & Elaborated & Regular & Yes & Yes & No \\
\hline $\begin{array}{l}\text { Frimberger } \\
2008^{9}\end{array}$ & Elaborated & Regular & Yes & Yes & No \\
\hline $\begin{array}{c}\text { Grund } \\
2012^{18}\end{array}$ & Elaborated & Regular & Yes & Yes & No \\
\hline $\begin{array}{c}\text { Katanuma } \\
2014^{14}\end{array}$ & Elaborated & Regular & Yes & No & N/A \\
\hline $\begin{array}{c}\text { Schneider } \\
2014^{6}\end{array}$ & Simple & $\begin{array}{l}\text { Regular and } \\
\text { inverse }\end{array}$ & No & No & N/A \\
\hline $\begin{array}{c}\text { Actual } \\
\text { EMS }\end{array}$ & Elaborated & Inverse & Yes & Yes & No \\
\hline
\end{tabular}

EMS, ERCP mechanical simulator.

\subsection{Efficacy scores}

We conducted this prospective comparative study to compare the efficacy of different endoscopic sphincterotomy techniques in Billroth II anatomy by using a novel validated mechanical ERCP simulator. We compared the use of standard sphincterotome, a Billroth II sphincterotome, and a needle-knife endoscopic sphincterotomy guided by endoprosthesis. For each technique, a standard endoscope and a side-viewing endoscope were used. The procedures were performed by 10 ERCP endoscopists who had a large experience in performing ERCP in patients with postsurgical anatomy. Each technique was evaluated regarding the efficacy and the duration of the EST. The efficacy 
was assessed by a blinded expert endoscopist by post hoc analysis of the video clips of the cut papillae and was given an efficacy score.

Five of the participants were preferring the use of needle-knife endoscopic sphincterotomy guided by endoprosthesis, three were preferring B II sphincterotome, one was preferring standard sphincterotome and one was preferring balloon dilatation.

In our study, we demonstrate that the efficacy of both the needle-knife EST guided by endoprosthesis and the BII sphincterotome was significantly superior to the standard sphincterotome $(p<0.001$ and $p=0.001)$. Also, the needle-knife guided by an endoprosthesis also being superior to the BII sphincterotome $(p=0.017)$. Therefore, needle knife EST guided by an endoprosthesis is suited best for EST in postsurgical anatomy. On the other hand, the procedure using the Bll sphincterotome was significantly shorter in duration than both the needle-knife EST guided by endoprosthesis $(p=0.005)$ and the standard sphincterotome $(p=0.004)$. We also showed that there is no significant difference between the forward-viewing endoscope and the side-viewing endoscope when the same cutting technique is used, regarding the EST efficacy $(p=0.910)$ and the duration $(p=0.219)$. Our findings are in accordance with the results by Kim et al. where the forwardviewing endoscope was as effective as the side viewing endoscope to achieve a successful EST with success rate of $83 \%$ and $80 \%$ respectively. However, due to easier and safer passage to the papilla the forward-viewing endoscope was recommended in that study (Kim, Lee, Lee, Myung, Yoo, Seo, \& Min, 1997). They reported jejunal perforation occurred in 4/ 20 patients by using a side viewing endoscope vs no perforations when forward viewing endoscope was used (Kim, Lee, Lee, Myung, Yoo, Seo, \& Min, 1997). A low success rate of standard sphincterotome is in accordance with an early trial by Safrany et al. EST was successful by using a standard sphincterotome at the first attempt in only $9 \%(n=35)$ of cases where the incision was placed in the ideal cranial position. They finally achieved a successful cannulation with standard sphincterotome in $66 \%$ after up to 4 attempts. They also reported that using a forwardviewing endoscope did not solve the problem. (Safrany, Neuhaus, Portocarrero, \& Krause, 1980). Our study confirms this result where the standard sphincterotome has gathered poor mean efficacy scores of $2.2 \pm 3.0$ and $3.2 \pm 2.7$ when using side-viewing endoscope and forward-viewing endoscope respectively.

In contrast, and in accordance to our results, Bll sphincterotomes have shown favorable outcome in many studies. In a study by Hintze et al. a Bll sphincterotome was used, the 
success rate was 92\% ( $n=54)$ (Hintze, Veltzke, Adler, \& Abou-Rebyeh, 1997). Similarly, Osenes et al. (Osnes, Rosseland, \& Aabakken, 1986) and Costamagna group (Costamagna, Mutignani, Perri, Gabrielli, Locicero, \& Crucitti, 1994) have achieved success rates of $92 \%$ and $92.8 \%$ respectively. The design of the BII sphincterotome allowed safe cannulation of the papilla and sphincterotomy under endoscopic visualization.

Another approach adopted by van Buuren et al., where the EST was achieved by using a needle-knife sphincterotomy guided by biliary endoprosthesis, the success rate was $95 \%$ in total of 19 patients (van Buuren, Boender, Nix, \& van Blankenstein, 1995). This technique is attractive because it should be undertaken under complete endoscopic vision and the needle knife can be precisely controlled. Moreover, the presence of the endoprosthesis presents a clear guidance, indicating where and how deeply to cut. Various studies showed high success rates in cannulating the bile duct by using this technique (Ricci, Bertoni, Conigliaro, Contini, Mortilla, \& Bedogni, 1989; Siegel, Cohen, Kasmin, \& Veerappan, 1994). The high success rate of this technique in these studies are confirmed by our results. Beyond that, we found that needle knife sphincterotomy guided by an inserted plastic stent had superior results in comparison to other different techniques. On the other hand, we demonstrated that the BII sphincterotome required shorter duration in comparison to the needle-knife technique, which can be related to the time needed for the stent insertion prior to the use of the needle-knife. Nevertheless, timeconsumption for EST might not be relevant in a procedure where often most time is spent for reaching the papilla.

\subsection{Limitations}

Our study has some limitations. The passage of the endoscope to the papilla in terms of time needed and related problems cannot be investigated with the Bll simulator used. The reason for that is the absence of afferent loop simulation in this simulator. The study therefore is limited to the question which cutting device and which method can be the most suitable for EST after reaching and cannulating the papilla.

While it could be difficult to extrapolate a simulator based evaluation directly to clinical practice, it still can be a guide ensuring a better procedure by evaluating a procedure under standardized conditions (Leung, Lee, Wilson, Lim, \& Leung, 2008). Also multiple procedures and trials can be carried out safely in absence of complications and relatively over a short period. 
Another limitation of this study is lack of complete blinding. Although the reviewer was blinded form the type pf the techniques, the participants were not due to the nature of the study.

Furthermore, one of the attractive techniques, namely balloon dilatation of the papilla, could not be applied and tested in this study because the simulated papilla are not developed for this technique.

Finally, complications that can be encountered in real life practice during EST, like bleeding and perforation, could not be assessed in our study.

\subsection{Conclusion}

In conclusion, this study shows that the needle-knife EST guided by endoprosthesis was most time-consuming but was the most efficient EST technique in Bll and Roux-en-Y gastrectomy, followed by the Bll sphincterotome.

We do not recommend the use of the standard sphincterotome for such a procedure. Finally, after having reached the papilla, the type of the endoscope is of no importance regarding the efficacy of EST. 


\section{References:}

Aabakken, L., Holthe, B., Sandstad, O., Rosseland, A., \& Osnes, M. (1998). Endoscopic pancreaticobiliary procedures in patients with a Billroth II resection: a 10-year follow-up study. Ital J Gastroenterol Hepatol, 30(3), 301-305.

Aliperti, G. (1996). Complications related to diagnostic and therapeutic endoscopic retrograde cholangiopancreatography. Gastrointest Endosc Clin N Am, 6(2), 379-407.

Andriulli, A., Loperfido, S., Napolitano, G., Niro, G., Valvano, M. R., Spirito, F., Pilotto, A., \& Forlano, R. (2007). Incidence rates of post-ERCP complications: a systematic survey of prospective studies. Am J Gastroenterol, 102(8), 1781-1788. doi:10.1111/j.15720241.2007.01279.x

Ansell, J., Arnaoutakis, K., Goddard, S., Hawkes, N., Leicester, R., Dolwani, S., Torkington, J., \& Warren, N. (2013). The WIMAT colonoscopy suitcase model: a novel porcine polypectomy trainer. Colorectal Dis, 15(2), 217-223; discussion 223. doi:10.1111/j.14631318.2012.03122.x

Baron, T. H., Petersen, B. T., Mergener, K., Chak, A., Cohen, J., Deal, S. E., Hoffinan, B., Jacobson, B. C., Petrini, J. L., Safdi, M. A., Faigel, D. O., Pike, I. M., \& Endoscopy, Asge Acg Taskforce on Quality in. (2006). Quality indicators for endoscopic retrograde cholangiopancreatography. American Journal of Gastroenterology, 101(4), 892-897. doi:10.1111/j.1572-0241.2006.00675.x

Bergman, Jacques J. G. H. M., van Berkel, Anne-Marie, Bruno, Marco J., Fockens, Paul, Rauws, Erik A. J., Tijssen, Jan G. P., Tytgat, Guido N. J., \& Huibregtse, Kees. (2001). A randomized trial of endoscopic balloon dilation and endoscopic sphincterotomy for removal of bile duct stones in patients with a prior Billroth II gastrectomy. Gastrointestinal Endoscopy, 53(1), 19-26. doi:10.1067/mge.2001.110454

Bittner, J. G. th, Mellinger, J. D., Imam, T., Schade, R. R., \& Macfadyen, B. V., Jr. (2010). Face and construct validity of a computer-based virtual reality simulator for ERCP. Gastrointestinal Endoscopy, 71(2), 357-364. doi:10.1016/j.gie.2009.08.033

Bove, V., Tringali, A., Familiari, P., Gigante, G., Boskoski, I., Perri, V., Mutignani, M., \& Costamagna, G. (2015). ERCP in patients with prior Billroth II gastrectomy: report of 30 years' experience. Endoscopy, 47(7), 611-616. doi:10.1055/s-0034-1391567

Byun, J. W., Kim, J. W., Sung, S. Y., Jung, H. Y., Jeon, H. K., Park, H. J., Kim, M. Y., Kim, H. S., \& Baik, S. K. (2012). Usefulness of Forward-Viewing Endoscope for Endoscopic Retrograde Cholangiopancreatography in Patients with Billroth II Gastrectomy. Clin Endosc, 45(4), 397-403. doi:10.5946/ce.2012.45.4.397

Canard, Jean Marc, Lennon, Anne Marie, Létard, Jean-Christophe, Etienne, Jacques, \& Okolo, Patrick. (2011). CHAPTER 10 - Endoscopic retrograde cholangiopancreatography. In Gastrointestinal Endoscopy in Practice (pp. 370-465). Edinburgh: Churchill Livingstone.

Chun, S. Y., Kim, J. H., Moon, S. H., Lee, S. J., Lim, S., Park, J. W., Kang, H. S., Kim, S. E., Kang, K. J., \& Park, C. K. (2014). The Loop-Tip Wire for Selective Cannulation during ERCP in Patients with Billroth II Anastomosis: A Preliminary Feasibility Study. Hepatogastroenterology, 61(132), 897-901.

Classen, M., \& Demling, L. (1974). [Endoscopic sphincterotomy of the papilla of vater and extraction of stones from the choledochal duct (author's transl)]. Dtsch Med Wochenschr, 99(11), 496-497. doi:10.1055/s-0028-1107790

Cohen, S., Bacon, B. R., Berlin, J. A., Fleischer, D., Hecht, G. A., Loehrer, P. J., Sr., McNair, A. E., Jr., Mulholland, M., Norton, N. J., Rabeneck, L., Ransohoff, D. F., Sonnenberg, A., \& 
Vannier, M. W. (2002). National Institutes of Health State-of-the-Science Conference Statement: ERCP for diagnosis and therapy, January 14-16, 2002. Gastrointest Endosc, 56(6), 803-809. doi:10.1067/mge.2002.129875

Committee, Asge Standards of Practice, Chathadi, K. V., Chandrasekhara, V., Acosta, R. D., Decker, G. A., Early, D. S., Eloubeidi, M. A., Evans, J. A., Faulx, A. L., Fanelli, R. D., Fisher, D. A., Foley, K., Fonkalsrud, L., Hwang, J. H., Jue, T. L., Khashab, M. A., Lightdale, J. R., Muthusamy, V. R., Pasha, S. F., Saltzman, J. R., Sharaf, R., Shaukat, A., Shergill, A. K., Wang, A., Cash, B. D., \& DeWitt, J. M. (2015). The role of ERCP in benign diseases of the biliary tract. Gastrointest Endosc, 81(4), 795-803. doi:10.1016/j.gie.2014.11.019

Costamagna, G., Mutignani, M., Perri, V., Gabrielli, A., Locicero, P., \& Crucitti, F. (1994). Diagnostic and therapeutic ERCP in patients with Billroth II gastrectomy. Acta Gastroenterol Belg, 57(2), 155-162.

Cotton, P. B. (1972). Cannulation of the papilla of Vater by endoscopy and retrograde cholangiopancreatography (ERCP). Gut, 13(12), 1014-1025.

Cotton, P. B. (1994). Outcomes of endoscopy procedures: struggling towards definitions. Gastrointest Endosc, 40(4), 514-518.

Cotton, P. B., Blumgart, L. H., Davies, G. T., Pierce, J. W., Salmon, P. R., Burwood, R. J., Lawrie, B. W., \& Read, A. E. (1972). Cannulation of papilla of vater via fiber-duodenoscope. Assessment of retrograde cholangiopancreatography in 60 patients. Lancet, 1(7741), 5358.

Cotton, P. B., Eisen, G. M., Aabakken, L., Baron, T. H., Hutter, M. M., Jacobson, B. C., Mergener, K., Nemcek, A., Jr., Petersen, B. T., Petrini, J. L., Pike, I. M., Rabeneck, L., Romagnuolo, J., \& Vargo, J. J. (2010). A lexicon for endoscopic adverse events: report of an ASGE workshop. Gastrointest Endosc, 71(3), 446-454. doi:10.1016/j.gie.2009.10.027

Cotton, P. B., Lehman, G., Vennes, J., Geenen, J. E., Russell, R. C., Meyers, W. C., Liguory, C., \& Nickl, N. (1991). Endoscopic sphincterotomy complications and their management: an attempt at consensus. Gastrointest Endosc, 37(3), 383-393.

Demarquay, J. F., Dumas, R., Buckley, M. J., Conio, M., Zanaldi, H., Hastier, P., Caroli-Bosc, F. X., \& Delmont, J. P. (1998). Endoscopic retrograde cholangiopancreatography in patients with Billroth II gastrectomy. Ital J Gastroenterol Hepatol, 30(3), 297-300.

Desilets, D. J., Banerjee, S., Barth, B. A., Kaul, V., Kethu, S. R., Pedrosa, M. C., Pfau, P. R., Tokar, J. L., Varadarajulu, S., Wang, A., Wong Kee Song, L. M., \& Rodriguez, S. A. (2011). Endoscopic simulators. Gastrointest Endosc, 73(5), 861-867. doi:10.1016/j.gie.2011.01.063

Dong, S. H. (2012). Tips for Successful Endoscopic Retrograde Cholangiopancreatography in Patients with Billroth II Gastrectomy. Clin Endosc, 45(4), 343-344. doi:10.5946/ce.2012.45.4.343

Feitoza, A. B., \& Baron, T. H. (2001). Endoscopy and ERCP in the setting of previous upper GI tract surgery. Part I: reconstruction without alteration of pancreaticobiliary anatomy. Gastrointest Endosc, 54(6), 743-749.

Fleischer, D. E. (1994). Better definition of endoscopic complications and other negative outcomes. Gastrointest Endosc, 40(4), 511-514.

Freeman, M. L., \& Guda, N. M. (2005). ERCP cannulation: a review of reported techniques. Gastrointest Endosc, 61(1), 112-125.

Freeman, M. L., Nelson, D. B., Sherman, S., Haber, G. B., Herman, M. E., Dorsher, P. J., Moore, J. P., Fennerty, M. B., Ryan, M. E., Shaw, M. J., Lande, J. D., \& Pheley, A. M. (1996). Complications of endoscopic biliary sphincterotomy. N Engl J Med, 335(13), 909-918. doi:10.1056/nejm199609263351301 
Frimberger, E., Abdelhafez, M., Schmid, R. M., \& von Delius, S. (2016). A novel mechanical simulator for cannulation and sphincterotomy after Billroth II or Roux-en-Y reconstruction. Endosc Int Open, 4(8), E922-926. doi:10.1055/s-0042-111905

Frimberger, E., von Delius, S., Rosch, T., Karagianni, A., Schmid, R. M., \& Prinz, C. (2008). A novel and practicable ERCP training system with simulated fluoroscopy. Endoscopy, 40(6), 517520. doi:10.1055/s-2007-995456

Giljaca, V., Gurusamy, K. S., Takwoingi, Y., Higgie, D., Poropat, G., Stimac, D., \& Davidson, B. R. (2015). Endoscopic ultrasound versus magnetic resonance cholangiopancreatography for common bile duct stones. Cochrane Database Syst Rev(2), CD011549. doi:10.1002/14651858.CD011549

Gurusamy, K. S., Kumar, S., \& Davidson, B. R. (2013). Prophylactic gastrojejunostomy for unresectable periampullary carcinoma. Cochrane Database Syst Rev(2), Cd008533. doi:10.1002/14651858.CD008533.pub3

Hekimoglu, K., Ustundag, Y., Dusak, A., Erdem, Z., Karademir, B., Aydemir, S., \& Gundogdu, S. (2008). MRCP vs. ERCP in the evaluation of biliary pathologies: review of current literature. J Dig Dis, 9(3), 162-169.

Hintze, R. E., Adler, A., Veltzke, W., \& Abou-Rebyeh, H. (1997). Endoscopic access to the papilla of Vater for endoscopic retrograde cholangiopancreatography in patients with billroth II or Roux-en-Y gastrojejunostomy. Endoscopy, 29(2), 69-73. doi:10.1055/s-2007-1004077

Hintze, R. E., Veltzke, W., Adler, A., \& Abou-Rebyeh, H. (1997). Endoscopic sphincterotomy using an S-shaped sphincterotome in patients with a Billroth II or Roux-en-Y gastrojejunostomy. Endoscopy, 29(2), 74-78. doi:10.1055/s-2007-1004078

Houghton, A. D., Liepins, P., Clarke, S., \& Mason, R. (1996). Iso- or antiperistaltic anastomosis: does it matter? J R Coll Surg Edinb, 41(3), 148-151.

Illingworth, C. F. (1960). Post-gastrectomy syndromes: a review. Gut, 1, 183-192.

Jean Marc Canard, Jean-Christophe Létard, Laurent Palazzo, Ian Penman, Anne Marie Lennon. (2011). Gastrointestinal endoscopy in practice: Elsevier Limited.

Jex, R. K., van Heerden, J. A., Wolff, B. G., Ready, R. L., \& Ilstrup, D. M. (1987). Gastrointestinal anastomoses. Factors affecting early complications. Ann Surg, 206(2), 138-141.

Jirapinyo, P., Kumar, N., \& Thompson, C. C. (2015). Validation of an endoscopic part-task training box as a skill assessment tool. Gastrointest Endosc, 81(4), 967-973. doi:10.1016/j.gie.2014.08.007

Kasugai, T., Kuno, N., Aoki, I., Kizu, M., \& Kobayashi, S. (1971). Fiberduodenoscopy: analysis of 353 examinations. Gastrointest Endosc, 18(1), 9-16.

Katanuma, A., Itoi, T., Umeda, J., Tonozuka, R., Mukai, S., Yane, K., Kin, T., Matsumoto, K., Matsumori, T., Gon, K., Takaki, R., \& Tomonari, A. (2014). A novel dry model for practicable sphincterotomy and precut needle knife sphincterotomy. Gastroenterol Res Pract, 2014, 908693. doi:10.1155/2014/908693

Kawai, K., Akasaka, Y., Murakami, K., Tada, M., \& Koli, Y. (1974). Endoscopic sphincterotomy of the ampulla of Vater. Gastrointest Endosc, 20(4), 148-151.

Kikuyama, M., Sasada, Y., Matsuhashi, T., Ota, Y., \& Nakahodo, J. (2009). ERCP afterRoux-en-Y reconstruction can be carried out using an oblique-viewing endoscope with an overtube. Dig Endosc, 21(3), 180-184. doi:10.1111/j.1443-1661.2009.00882.x

Kim, M. H., Lee, S. K., Lee, M. H., Myung, S. J., Yoo, B. M., Seo, D. W., \& Min, Y. I. (1997). Endoscopic retrograde cholangiopancreatography and needle-knife sphincterotomy in patients with Billroth II gastrectomy: a comparative study of the forward-viewing endoscope and the side-viewing duodenoscope. Endoscopy, 29(2), 82-85. doi:10.1055/s2007-1004080 
Klaus F.R. Schiller, Roy Cockell, Richard H. Hunt, Bryan F. Warren. (2002). Atlas of Gastrointestinal Endoscopy and Related Pathology, 2nd Edition.: Blackwell Science Ltd.

Lee, Y. T. (2004). Cap-assisted endoscopic retrograde cholangiopancreatography in a patient with a Billroth II gastrectomy. Endoscopy, 36(7), 666. doi:10.1055/s-2004-814558

Leung, J. W., Lee, J. G., Rojany, M., Wilson, R., \& Leung, F. W. (2007). Development of a novel ERCP mechanical simulator. Gastrointestinal Endoscopy, 65(7), 1056-1062. doi:10.1016/j.gie.2006.11.018

Leung, J. W., Lee, W., Wilson, R., Lim, B. S., \& Leung, F. W. (2008). Comparison of accessory performance using a novel ERCP mechanical simulator. Endoscopy, 40(12), 983-988. doi:10.1055/s-2008-1077777

Lin, L. F., Siauw, C. P., Ho, K. S., \& Tung, J. C. (1999). ERCP in post-Billroth II gastrectomy patients: emphasis on technique. Am J Gastroenterol, 94(1), 144-148. doi:10.1111/j.15720241.1999.00785.x

Mallery, J. S., Baron, T. H., Dominitz, J. A., Goldstein, J. L., Hirota, W. K., Jacobson, B. C., Leighton, J. A., Raddawi, H. M., Varg, J. J., 2nd, Waring, J. P., Fanelli, R. D., Wheeler-Harbough, J., Eisen, G. M., \& Faigel, D. O. (2003). Complications of ERCP. Gastrointest Endosc, 57(6), 633-638.

Markman, H. D. (1969). A new system for teaching proctosigmoidoscopic morphology. Am J Gastroenterol, 52(1), 65-69.

Martinek, J., Suchanek, S., Stefanova, M., Rotnaglova, B., Zavada, F., Strosova, A., \& Zavoral, M. (2011). Training on an ex vivo animal model improves endoscopic skills: a randomized, single-blind study. Gastrointest Endosc, 74(2), 367-373. doi:10.1016/j.gie.2011.04.042

Matthes, K., \& Cohen, J. (2006). The Neo-Papilla: a new modification of porcine ex vivo simulators for ERCP training (with videos). Gastrointestinal Endoscopy, 64(4), 570-576. doi:10.1016/j.gie.2006.02.046

McConnell, R. A., Kim, S., Ahmad, N. A., Falk, G. W., Forde, K. A., Ginsberg, G. G., Jaffe, D. L., Makar, G. A., Long, W. B., Panganamamula, K. V., \& Kochman, M. L. (2012). Poor discriminatory function for endoscopic skills on a computer-based simulator. Gastrointest Endosc, 76(5), 993-1002. doi:10.1016/j.gie.2012.07.024

McCune, W. S., Shorb, P. E., \& Moscovitz, H. (1968). Endoscopic cannulation of the ampulla of vater: a preliminary report. Ann Surg, 167(5), 752-756.

Moreels, T. G. (2014). Endoscopic retrograde cholangiopancreatography in patients with altered anatomy: How to deal with the challenges? World J Gastrointest Endosc, 6(8), 345-351. doi:10.4253/wjge.v6.i8.345

Nakahara, K., Okuse, C., Suetani, K., Morita, R., Michikawa, Y., Ozawa, S., Hosoya, K., Nomoto, M., Kobayashi, S., Otsubo, T., \& Itoh, F. (2015). Endoscopic retrograde cholangiography using an anterior oblique-viewing endoscope in patients with altered gastrointestinal anatomy. Dig Dis Sci, 60(4), 944-950. doi:10.1007/s10620-014-3386-x

Neumann, M., Mayer, G., Ell, C., Felzmann, T., Reingruber, B., Horbach, T., \& Hohenberger, W. (2000). The Erlangen Endo-Trainer: life-like simulation for diagnostic and interventional endoscopic retrograde cholangiography. Endoscopy, 32(11), 906-910. doi:10.1055/s2000-8090

Okabe, Y., Ishida, Y., Kuraoka, K., Ushijima, T., \& Tsuruta, O. (2014). Endoscopic bile duct and/or pancreatic duct cannulation technique for patients with surgically altered gastrointestinal anatomy. Dig Endosc, 26 Suppl 2, 122-126. doi:10.1111/den.12274

Osnes, M., Rosseland, A. R., \& Aabakken, L. (1986). Endoscopic retrograde cholangiography and endoscopic papillotomy in patients with a previous Billroth-II resection. Gut, 27(10), 1193-1198. doi:10.1136/gut.27.10.1193 
Pach, R., Orzel-Nowak, A., \& Scully, T. (2008). Ludwik Rydygier--contributor to modern surgery. Gastric Cancer, 11(4), 187-191. doi:10.1007/s10120-008-0482-7

Park, C. H., Lee, W. S., Joo, Y. E., Kim, H. S., Choi, S. K., \& Rew, J. S. (2007). Cap-assisted ERCP in patients with a Billroth II gastrectomy. Gastrointest Endosc, 66(3), 612-615. doi:10.1016/j.gie.2007.04.024

Pasha, S. F., Acosta, R., Chandrasekhara, V., Chathadi, K. V., Eloubeidi, M. A., Fanelli, R., Faulx, A. L., Fonkalsrud, L., Khashab, M. A., Lightdale, J. R., Muthusamy, V. R., Saltzman, J. R., Shaukat, A., Wang, A., \& Cash, B. (2014). Routine laboratory testing before endoscopic procedures. Gastrointest Endosc, 80(1), 28-33. doi:10.1016/j.gie.2014.01.019

Petersen, B. T. (2002). ERCP outcomes: defining the operators, experience, and environments. Gastrointest Endosc, 55(7), 953-958.

Petri, G. (1985). [Our surgical heritage: the tragic destiny of the surgeon. Eugen Alexander Polya (1876-1944)]. Zentralb/ Chir, 110(1), 46-52.

Petter Cotton, Joseph Leung. (2005). Advanced digestive Endoscopy: ERCP: Blackwell Publishing Ltd.

Prat, F., Fritsch, J., Choury, A. D., Meduri, B., Pelletier, G., \& Buffet, C. (1997). Endoscopic sphincteroclasy: a useful therapeutic tool for biliary endoscopy in Billroth II gastrectomy patients. Endoscopy, 29(2), 79-81. doi:10.1055/s-2007-1004079

Ricci, E., Bertoni, G., Conigliaro, R., Contini, S., Mortilla, M. G., \& Bedogni, G. (1989). Endoscopic sphincterotomy in Billroth II patients: an improved method using a diathermic needle as sphincterotome and a nasobiliary drain as guide. Gastrointest Endosc, 35(1), 47-50.

Safrany, L., Neuhaus, B., Portocarrero, G., \& Krause, S. (1980). Endoscopic sphincterotomy in patients with Billroth II gastrectomy. Endoscopy, 12(1), 16-22. doi:10.1055/s-20071021704

Santoro, E. (2005). The history of gastric cancer: legends and chronicles. Gastric Cancer, 8(2), 7174. doi:10.1007/s10120-005-0325-8

Schneider, A. R., \& Schepp, W. (2014). Do it yourself: building an ERCP training system within 30 minutes (with videos). Gastrointestinal Endoscopy, 79(5), 828-832. doi:10.1016/j.gie.2014.01.006

Siegel, J. H., Cohen, S. A., Kasmin, F. E., \& Veerappan, A. (1994). Stent-guided sphincterotomy. Gastrointest Endosc, 40(5), 567-572.

Siu, W. T., Tang, C. N., Law, B. K., Chau, C. H., Yau, K. K., Yang, G. P., \& Li, M. K. (2004). Vagotomy and gastrojejunostomy for benign gastric outlet obstruction. J Laparoendosc Adv Surg Tech A, 14(5), 266-269. doi:10.1089/lap.2004.14.266

Soehendra, N., \& Reynders-Frederix, V. (1980). Palliative bile duct drainage - a new endoscopic method of introducing a transpapillary drain. Endoscopy, 12(1), 8-11. doi:10.1055/s2007-1021702

Stupart, D. A., Panieri, E., \& Dent, D. M. (2006). Gastrojejunostomy for gastric outlet obstruction in patients with gastric carcinoma. S Afr J Surg, 44(2), 52-54.

Sundaralingam, P., Masson, P., \& Bourke, M. J. (2015). Early Precut Sphincterotomy Does Not Increase Risk During Endoscopic Retrograde Cholangiopancreatography in Patients With Difficult Biliary Access: A Meta-analysis of Randomized Controlled Trials. Clin Gastroenterol Hepatol, 13(10), 1722-1729 e1722. doi:10.1016/j.cgh.2015.06.035

T, Billroth. (1881). Offenes Schreiben an Herrn Dr. Wittelshofer. Wien Med Wochenschr. (31), 162-165.

Takagi, K., Ikeda, S., Nakagawa, Y., Sakaguchi, N., Takahashi, T., Kumakura, K., Maruyama, M., Someya, N., Nakano, H., Takada, T., Takekoshi, T., \& Kin, T. (1970). Retrograde 
Pancreatography and Cholangiography by Fiber Duodenoscope. Gastroenterology, 59(3), 445-+.

Tse, F., Yuan, Y., Moayyedi, P., \& Leontiadis, G. I. (2013). Guide wire-assisted cannulation for the prevention of post-ERCP pancreatitis: a systematic review and meta-analysis. Endoscopy, 45(8), 605-618. doi:10.1055/s-0032-1326640

Urakami, Y. (1973). [Endoscopic pancreatocholangiography after Billroth II operation]. Nihon Shokakibyo Gakkai Zasshi, 70(9), 942-950.

van Buuren, H. R., Boender, J., Nix, G. A., \& van Blankenstein, M. (1995). Needle-knife sphincterotomy guided by a biliary endoprosthesis in Billroth II gastrectomy patients. Endoscopy, 27(3), 229-232. doi:10.1055/s-2007-1005676

Verdaasdonk, E. G., Stassen, L. P., Monteny, L. J., \& Dankelman, J. (2006). Validation of a new basic virtual reality simulator for training of basic endoscopic skills: the SIMENDO. Surg Endosc, 20(3), 511-518. doi:10.1007/s00464-005-0230-6

Vezakis, A., Fragulidis, G., \& Polydorou, A. (2015). Endoscopic retrograde cholangiopancreatography-related perforations: Diagnosis and management. World J Gastrointest Endosc, 7(14), 1135-1141. doi:10.4253/wjge.v7.i14.1135

Wang, P., Li, Z. S., Liu, F., Ren, X., Lu, N. H., Fan, Z. N., Huang, Q., Zhang, X., He, L. P., Sun, W. S., Zhao, Q., Shi, R. H., Tian, Z. B., Li, Y. Q., Li, W., \& Zhi, F. C. (2009). Risk factors for ERCPrelated complications: a prospective multicenter study. Am J Gastroenterol, 104(1), 31 40. doi:10.1038/ajg.2008.5

Wang, Y. G., Binmoeller, K. F., Seifert, H., Maydeo, A., \& Soehendra, N. (1996). A new guide wire papillotome for patients with Billroth II gastrectomy. Endoscopy, 28(2), 254-255. doi:10.1055/s-2007-1005438

Wiesner, W., Weiss, H. D., \& Anacker, H. (1972). [Preliminary results of retrograde pancreaticography by duodenoscopy in the diagnosis of chronic pancreatitis]. Dtsch Med Wochenschr, 97(26), 991-993. doi:10.1055/s-0028-1107482

Williams, E. J., Taylor, S., Fairclough, P., Hamlyn, A., Logan, R. F., Martin, D., Riley, S. A., Veitch, P., Wilkinson, M. L., Williamson, P. R., \& Lombard, M. (2007). Risk factors for complication following ERCP; results of a large-scale, prospective multicenter study. Endoscopy, 39(9), 793-801. doi:10.1055/s-2007-966723

Wu, W. G., Zhang, W. J., Gu, J., Zhao, M. N., Zhuang, M., Tao, Y. J., Liu, Y. B., \& Wang, X. F. (2014). Retrieval-balloon-assisted enterography for ERCP after Billroth II gastroenterostomy and Braun anastomosis. World J Gastroenterol, 20(31), 1092110926. doi:10.3748/wjg.v20.i31.10921

Young HS, Keeffe EB. (1998). Sleisenger \& Fordtran's Gastrointestinal and Liver Disease (6th ed.): WB Saunders, Philadelphia. 


\section{List of Figures}

Figure 1. Cannulation of the bile duct through the papilla by using a side viewing duodenoscope (Cancer Research UK / Wikimedia Commons)

Figure 2. Fluoroscopic image during ERC showing dilated bile duct with an inflated stone extraction balloon inside

Figure 3. Illustration of Billroth II reconstruction consists of an end-to-side gastrojejunal anastomosis (Cancer Research UK)

Figure 4. multiple fluoroscopic images for ERCP in Billroth II

Figure 5. Billroth II simulator fixed on an endoscopy trolley below the monitor. In the window of the simulator a guidewire inserted through the papilla is visible...35

Figure 6. Billroth II simulator. The sliding carriage, which is otherwise not visible, is pulled out for insertion of the papilla. The duodenum is mounted onto the carriage. In the window, the transparent bile duct is visible.

Figure 7. The papilla is inserted into the opening of duodenum and fixed to the mount by gently pressing its metal coil into the groove of the mount. The metal coil serves for grounding the papilla via the mount connected to a socket at the back. When the carriage is closed, the coil leads instruments inserted into the papilla into the bile duct. This can be viewed in the window of the simulator......37

Figure 8. The working length of the papilla, that is the portion protruding into the duodenum, is .......... adjustable according to the purpose of the given training. The working length is adjusted by varying the fixation point of the metal spring to the mount. On the left, a short portion of the papilla is visible inside the duodenum. A far protruding papilla (right) allows the trainee to practice a longer cut than in reality. This gives them a better opportunity to learn the handling of the sphincterotomes in combination with the application of HF current.

Figure 9. Endoscopic view of endoscopic sphincterotomy using needle knife guided by endoprosthesis and a side-viewing endoscope (technique no. 3).....39 
Figure 10. Endoscopic view of endoscopic sphincterotomy using Billroth II sphincterotome and a forward-viewing endoscope (technique no. 4).

Figure 11. Box-Plot shows the minimum, maximum, interquartile range and median value of efficacy of EST using different techniques. ( 0 completely unsuccessful, 1 very poor, 10 excellent; SVE = side-viewing duodenoscope, FVE = forward-viewing endoscope, SS = standard sphincterotome, $\mathrm{BII}=\mathrm{BII}$ sphincterotome, NK = needle-Knife EST guided by endoprosthesis).

Figure 12. Box-Plot shows the minimum, maximum, interquartile range and median value of duration of EST using different techniques (sec). (SVE = sideviewing endoscope, FVE = forward-viewing endoscope, SS = standard sphincterotome, BII = BII sphincterotome, NK = needle-Knife EST guided by endoprosthesis. 


\section{List of Tables}

Table 1. Classification of site, timing, and severity of complications related to endoscopic retrograde cholangiopancreatography (ERCP).

Table 2. Grading system for the major complications of endoscopic retrograde

cholangiopancreatography (ERCP) and endoscopic sphincterotomy.

Table 3: The endoscopic experience of the participants

Table 4. Efficacy of endoscopic sphincterotomy. Blinded videotapes of cut papillae were rated by an ERCP expert on a numeric rating scale.

Table 5. Time consumption (sec) of endoscopic sphincterotomy techniques calculated from the start with intubation of the simulator with the endoscope until the completion of the endoscopic sphincterotomy.

Table 6: Indications of ERCP in patients with prior Billroth II gastrectomy. 48

Table 7. Comparison of different mechanical ERCP simulation models 


\section{Acknowledgement}

Firstly, I would like to express my sincere gratitude to my supervisor Prof. Roland M Schmid for the continuous support of my study and related research, for his patience, motivation, and immense knowledge. His guidance helped me in all the time of research and writing of this thesis.

My sincere thanks also go to my mentor Dr. Michael Quante and to Dr. Stefan von Delius who provided me an opportunity to join their team, and who gave access to the endoscopy and research facilities. Without they precious support it would not be possible to conduct this research.

Last but not the least, I would like to thank my family: my parents and to my wife and son for supporting me spiritually throughout writing this thesis and my life in general. 